\title{
Microstructural Characterization and Mechanical Behaviour of SiC and Kaoline Reinforced Aluminium Metal Matrix Composites Fabricated through Powder Metallurgy Technique
}

venkatesh vavilada ( $\sim$ vssvenkateshnits@gmail.com )

National Institute of Technology Silchar https://orcid.org/0000-0001-8639-8707

Ashish B Deoghare

National Institute of Technology Silchar

\section{Research Article}

Keywords: Powder metallurgy, Kaoline reinforcement, Mechanical properties, Fractography

Posted Date: April 9th, 2021

DOI: https://doi.org/10.21203/rs.3.rs-402620/v1

License: (c) (1) This work is licensed under a Creative Commons Attribution 4.0 International License.

Read Full License 


\title{
Microstructural Characterization and Mechanical Behaviour of SiC and Kaoline reinforced Aluminium Metal Matrix Composites Fabricated through powder metallurgy Technique
}

\author{
V.S.S Venkatesh ${ }^{1}$, Ashish B Deoghare ${ }^{2}$ \\ 1,2 Department of Mechanical Engineering, National Institute of Technology \\ Silchar, Assam, India
}

Correspondence to vssvenkateshnits@gmail.com

\begin{abstract}
In this study, the effect of naturally available and low-cost kaoline particles on the microstructural and mechanical behaviour of $\mathrm{Al}-\mathrm{SiC}$ - Kaoline Hybrid metal matrix composite was investigated. Al-10\% SiC- $\mathrm{x} \%$ Kaoline ( $\mathrm{X}=0,2,4,6,8)$ composite samples were fabricated through powder metallurgy technique by applying a compaction pressure of $350 \mathrm{MPa}$. The fabricated composite samples were subjected to Density, Hardness, tensile and impact tests to study the mechanical behaviour of fabricated hybrid composite. The presence of $\mathrm{SiC}$ and Kaoline reinforcements was confirmed by using SEM and X-Ray Diffraction analysis. It was observed that the maximum ultimate tensile strength (U.T.S) and maximum Yield Strength (Y.S) of the hybrid composite were found to be $263 \mathrm{MPa}$ and $202 \mathrm{MPa}$ for $\mathrm{Al}-10 \% \mathrm{SiC}-$ 4\%kaoline reinforcement. The formation of the intermetallic compound such as $\mathrm{Al}_{2} \mathrm{Cu}$ was observed in XRD and SEM analysis for Al-10\% SiC-6\% kaoline and Al-10\% SiC-8\% of kaoline reinforcement which leads to decrease in the U.T.S and Y.S of fabricated specimens. The impact strength of $\mathrm{Al}-10 \% \mathrm{SiC}-8 \%$ kaoline found to be decreased by $44.4 \%$ compared to unreinforced Aluminium due to the presence of harder $\mathrm{SiC}$ and Kaoline reinforcements particles. To study the fracture mechanism, Scanning Electron Microscopy study was carried on the fractured Tensile specimens which reveal that ductile fracture in unreinforced $\mathrm{Al}, \mathrm{Al}-10 \%$ $\mathrm{SiC}, \mathrm{Al}-10 \% \mathrm{SiC}-2 \%$ Kaoline due to the formation of dimples and Brittle fracture
\end{abstract}


was observed in $\mathrm{Al}-10 \% \mathrm{SiC}-4 \%$ Kaoline, Al-10\% SiC-6\% Kaoline and Al-10\% $\mathrm{SiC}-8 \%$ Kaoline due to the existence of cleavages and microcracks.

Keywords Powder metallurgy. Kaoline reinforcement. Mechanical properties. Fractography

\section{Introduction}

Hybrid Aluminium metal matrix composites contain two or more reinforcement elements dispersed in the Aluminium matrix phase, finds application in fabricating brake calliper, piston and rocker arms in the automobile industry due to their superior properties like high strength to weight ratio, higher hardness, higher compressive strength and higher ductility[1,2]. The incorporation of harder ceramic reinforcements into the softer aluminium matrix enhances the hardness and reduces the ductility of base matrix material [3-5]. The improved mechanical and metallurgical properties of the composite can be achieved by the appropriate selection of the fabrication process and the type of reinforcement particles dispersed in the matrix phase $[6,7]$. The evaluation of composite materials can be classified into different stages. In the first stage single hard reinforcement material is reinforced into the softer aluminium matrix to enhance to properties of the matrix material. The reinforcement material can be a discontinuous type (particles, whiskers and short fibers) or continuous type (fibers). Among these particle reinforced like oxides $\left(\mathrm{Al}_{2} \mathrm{O}_{3}, \mathrm{ZrO}_{2}, \mathrm{MgO}\right.$ ), carbides ( $\mathrm{TiC}, \mathrm{SiC}, \mathrm{B}_{4} \mathrm{C}$ ) and Nitrides ( $\mathrm{BN}, \mathrm{AlN}$ ) are widely used as a dispersed phase in aluminium matrix material [8-11]. In the second stage, hybrid metal matrix composites were introduced to enhance the properties of composite material than with single reinforcement attributed to improved mechanical properties [12]. In the third stage, incorporation of industrial waste like fly ash and agro-waste like bagasse ash, corn con ash, bean shell waste ash etc., are reinforced in matrix material along with harder ceramic reinforcements without 
deteriorating the properties of composite material[13-15]. Recently there is growing interest in the synthesis of composite material with cheaper reinforcements which improves the mechanical properties of the composite material. Kaoline is a naturally available and low-cost reinforcement material which contains elements like $\mathrm{SiO}_{2}$ (45.6\%), $\mathrm{Al}_{2} \mathrm{O}_{3}(38.4 \%), \mathrm{Fe}_{2} \mathrm{O}_{3}(0.4 \%), \mathrm{TiO}_{2}(1.5 \%), \mathrm{CaO}(0.06 \%), \mathrm{MgO}(0.05 \%)$ which improves the properties of base $\mathrm{Al}$ matrix material. Hence an attempt has been made to reinforce Kaoline as secondary phase reinforcements in the Al matrix.

In this present work, Al-SiC-Kaoline HMMC was fabricated through powder metallurgy technique by varying the Kaoline percentage from $0 \%$ to $8 \%$ and the effect of kaoline on the mechanical properties like Hardness, Tensile strength, Impact strength are investigated. The distribution of reinforcements and formation of intermetallic compounds are analyzed with X-ray diffraction analysis (XRD) and scanning electron microscope (SEM) with energy dispersive x-ray analysis (EDS) analysis. The fractured tensile samples were subjected to Fractography analysis to know the type of fracture that occurred in the fabricated samples.

Table 1. Chemical composition of kaoline reinforcement

\begin{tabular}{lllllllll}
$\mathrm{SiO}_{2}$ & $\mathrm{Al}_{2} \mathrm{O}_{3}$ & $\mathrm{Fe}_{2} \mathrm{O}_{3}$ & $\mathrm{TiO}_{2}$ & $\mathrm{CaO}$ & $\mathrm{MgO}$ & $\mathrm{K}_{2} \mathrm{O}$ & $\mathrm{NaO}_{2}$ & L.O.I \\
\hline 45.6 & 38.4 & 0.4 & 1.5 & 0.06 & 0.05 & 0.18 & 0.03 & 13.8
\end{tabular}

\section{Experimental Procedure:}

The Aluminium matrix powder mixed with a pre-determined quantity of $\mathrm{SiC}$ particles having a particle size less than $20 \mu \mathrm{m}$ (Fig. 1a) and Kaoline particles having a size less than $20 \mu \mathrm{m}$ (Fig. 1b) to prepare Al-10\% SiC- $\mathrm{x} \%$ Kaoline $(\mathrm{x}=0,2,4,6,8)$ hybrid composite. The sequence of processes that fallowed during the fabrication of composite is shown in Fig. 2. The as-received matrix and reinforcement powders are 
initially placed in the planetary high energy ball mill (Pulverisette 5 classic Frittsch $\mathrm{GmbH})$ to disperse the reinforcement powders uniformly throughout the matrix material and to induce strain hardening effect in the powders [2]. Ball milling was carried out under an inert Argon gas atmosphere to prevent the oxidation of powders during the mechanical milling process. $1.5 \%$ stearic acid was added to the powders as a process control agent (PCA) to prevent excessive cold welding between the powders and to avoid the welding between the powders and the surface of the balls [1]. After the ball milling process, these milled powders are compacted to the desired shape in $\mathrm{H}-13$ steel die by applying a pressure of $350 \mathrm{MPa}$ with the cross-head movement of punch was $1 \mathrm{mms}^{-1}$ to initiate the cold welding between the blended powders. The mixture of Acetone and zinc stearate applied on the outer surface of the punch and inner surface of the die as a lubricant for easy ejection of the compacted specimen from the punch and die assembly and to reduce the friction on the surfaces of the die $[16,17]$. The process parameters used in this process are shown in Table 2 [18]. The cold compacted samples were subjected to the sintering process in a muffle furnace for $3 \mathrm{~h}$ at $620^{\circ} \mathrm{C}$ with a temperature rise of $10^{\circ} \mathrm{C} / \mathrm{min}$ and allowed to cool the samples inside the furnace.

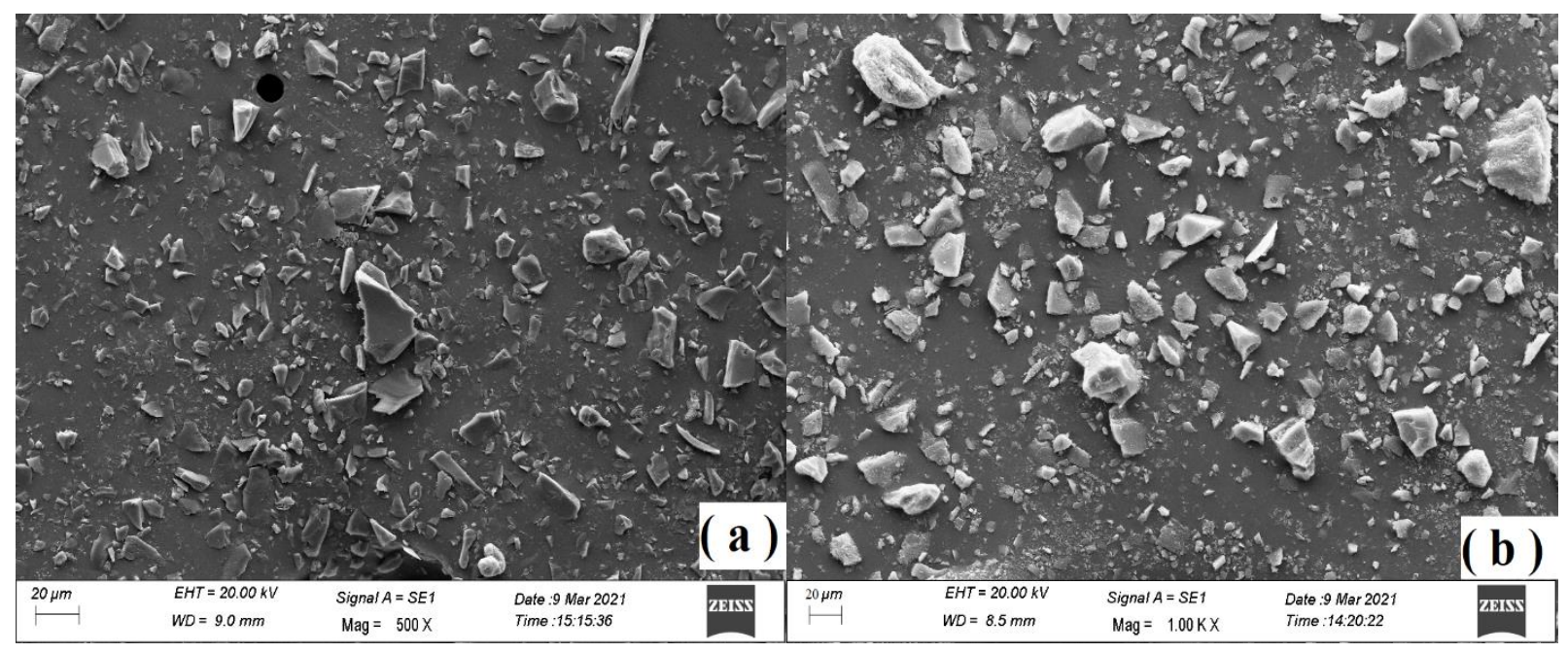

Fig. 1 Particle sizes of (a) SiC reinforcement, (b) Kaoline reinforcement. 


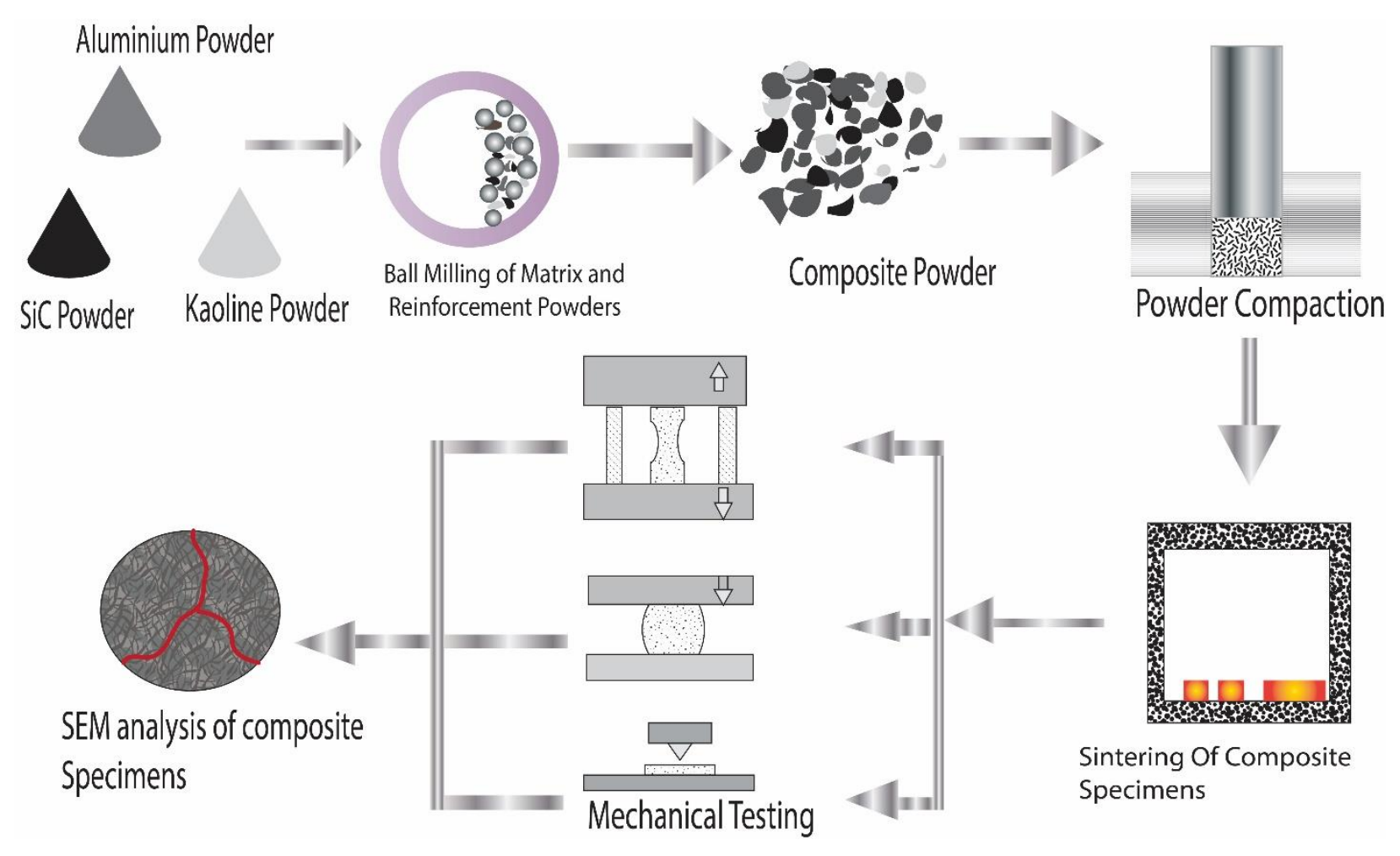

Fig. 2 Schematic diagram for powder metallurgy process

Table 2. Process parameters for ball milling process

\begin{tabular}{|l|l|}
\hline Milling Speed & $300 \mathrm{rpm}$ \\
\hline Ball to powder ratio & $10: 1$ \\
\hline Milling time & $3 \mathrm{~h}$ \\
\hline Process Control Agent ( PCA) & Stearic Acid \\
\hline Vial material & Hardened tungsten Carbide \\
\hline Ball material & Stainless steel \\
\hline
\end{tabular}

\section{Characterization of the fabricated composite}

The developed composite was tested to determine its mechanical and morphological characteristics. The numerous tests conducted for the characterization of developed composite are discussed below. 


\subsection{Morphological Characterization}

\subsubsection{X-Ray Diffraction (XRD) Analysis}

The elemental phases present in the fabricated samples were analyzed by using XRD. XRD was conducted on a fully computerized PANalytical powder X-ray diffractometer by supplying $40 \mathrm{KV}$ voltage and $20 \mathrm{~mA}$ current. The generated XRD spectra were taken at an angle (20) ranging from $10^{\circ}$ to $90^{\circ}$ with a step size of $0.02^{0}$.

\subsubsection{Tungsten Scanning Electron Microscopy (WSEM) analysis:}

The morphology and elemental composition of fabricated composite specimens are investigated on Carl Zeiss EVO 50 high resolution scanning electron microscope equipped with an energy dispersive x-ray (EDS) analyzer. To check the distribution of reinforcements in the matrix, the prepared samples were grinded on the belt grinder by using abrasive papers with grid sizes $600,800,1200,1800,2400$. Finally, these specimens are polished using $2 \mu \mathrm{m}$ and then $0.5 \mu \mathrm{m}$ diamond paste on a twindisc polisher. The composite samples are etched by using Keller's reagent (Mixture of Distilled water (190 ml), Nitric Acid (5ml), Hydrochloric Acid (3ml) and Hydrofluoric Acid $(2 \mathrm{ml})$ ) for $30 \mathrm{~s}$ to reveal the grains and microstructure at the micron level. The composite specimens are analyzed at a magnification range of 500X-5000X.

\subsection{Physical Characterization}

\subsubsection{Density and porosity Calculations}

Composite samples having dimension $30 \mathrm{~mm}$ dia and $10 \mathrm{~mm}$ length was made by using compaction die [3]. The density of fabricated samples was determined by using the Archimedes principle [4]. The mass of the samples in the air was found by using an electronic weighing machine with the least count of $10^{-3} \mathrm{~g}[4,5]$. Liquid displacement technique used to measure the mass of the composite specimens in 
water. According to Archimedes principle, the Density of the specimen was calculated by the following Eq. (1).

$$
\rho_{\text {Measured }}=\frac{w}{w-w_{1}} \rho_{1}
$$

$\rho_{\text {Measured }}=$ Measured density of the sample

$\mathrm{w}=$ Weight of the sample in air

$\mathrm{w}_{1}=$ Weight of the sample in distilled water

$\rho_{1}=$ Density of water

The porosity of the composite sample was determined by using the law of mixtures. The mathematical representation of \% porosity calculation is represented in the Eq. 2

$$
\begin{aligned}
& \% \text { Porosity }=\left(\frac{\rho_{\text {theoritical }}-\rho_{\text {measured }}}{\rho_{\text {theoritical }}}\right) * 100---(2) \\
& \rho_{\text {theoritical }}=\rho_{\text {matrix }} \times V_{\text {matrix }}+\rho \text { reinforcement } \times \\
&
\end{aligned}
$$

\subsection{Mechanical Characterization}

\subsubsection{Hardness measurement}

The Microhardness of the fabricated composite samples was measured as per ASTM E384-16 standards by using ECONOMET VH1MD Vickers Microhardness testing by applying a load of $25 \mathrm{~N}$ with $10 \mathrm{~s}$ dwell time [19]. The average of five hardness values was considered for each sample for better accuracy of results.

\subsubsection{Tensile test}

To correlate the $\%$ reinforcement on the ultimate tensile strength (U.T.S) and yield strength (Y.S) of composites, Micro tensile test was conducted on a universal testing machine (M-30) model with crosshead movement of $0.5 \mathrm{~mm} / \mathrm{min}$. Tensile specimens were fabricated according to ASTM E8 model having a gauge length of $25 \mathrm{~mm}, 6$ 
$\mathrm{mm}$ thickness and $6 \mathrm{~mm}$ gauge width as shown in Fig. 3a. The average of three readings was considered to minimize the uncertainty in the tensile test results.

\subsubsection{Impact test}

The prepared composite samples were subjected to the Charpy impact test according to ASTM A370 having a notch area of $100 \mathrm{~mm}^{2}$ as shown in Fig. 3b [20]. Initially, the testing apparatus was set at $10 \mathrm{kgm}$ for $\mathrm{e}_{1}$ reading. The final reading for all prepared composite specimens during the experiment was recorded as $\mathrm{e}_{2}$. Three trials were conducted for each $\%$ composition and the corresponding average value was taken for Charpy impact strength. The Charpy impact value was found by using the following Eq. (3).

Charpy impact value $(\mathrm{e})=\mathrm{e}_{1}-\mathrm{e}_{2}(\mathrm{Kgm})$
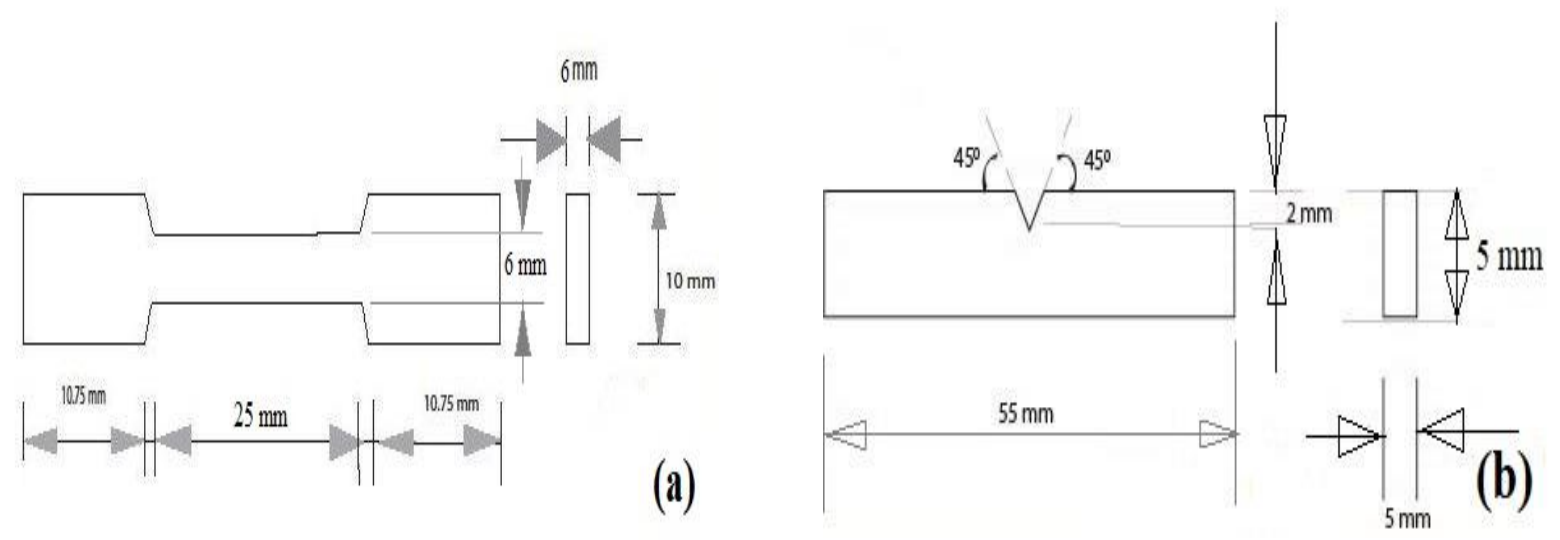

Fig. 3 Specimen dimension dimensions for (a) Tensile test, (b) Impact Test

\section{Results and Discussion}

\subsection{Morphological Results}

\subsubsection{XRD Analysis}

The XRD patterns of as received Al, SiC and Kaoline powders are shown in Fig. 4. The presence of $\mathrm{Al}_{2} \mathrm{O}_{3}, \mathrm{SiO}_{2}, \mathrm{Cao} / \mathrm{MgO}, \mathrm{TiO}_{2}$ peaks were identified in the XRD pattern of Kaoline as shown in Fig. 4. XRD patterns of Al-10\% SiC-6\% Kaoline and Al-10\% SiC-6\% Kaoline reveals the formation of brittle clusters (Fig. 5) and the 
corresponding peak $\mathrm{Al}_{2} \mathrm{Cu}$ was observed at an angle of $38^{0}$ which improves the brittleness and reduces the ductility of the composite. The obtained $\mathrm{Al}_{2} \mathrm{Cu}$ peak corresponding to these clusters was fairly accurate with the peak obtained by Gatea et al., [21]. No oxides peaks were identified in XRD patterns of fabricated composite. The absence of oxide peaks in the composite samples signifies that the achievement of good powder metallurgical composite samples. The increase in kinetic energy of matrix and reinforcement particles during sintering of specimens and the entrapped oxygen in the material will undergo chemical reaction at higher sintering temperatures are the main causes for the formation of clusters that degrades the strength of the composite[22-24].

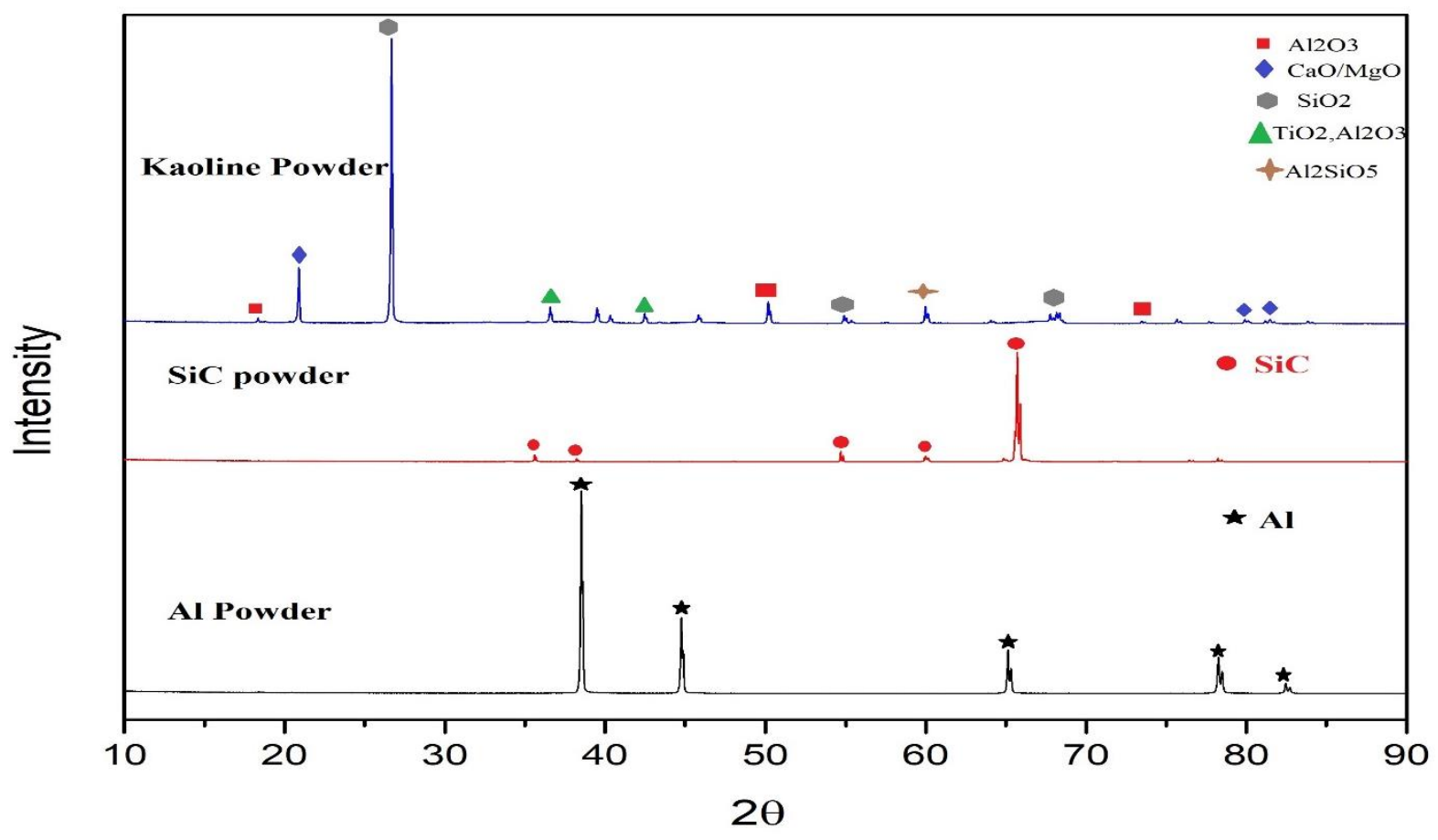

Fig. 4 XRD pattern for as-received powders 


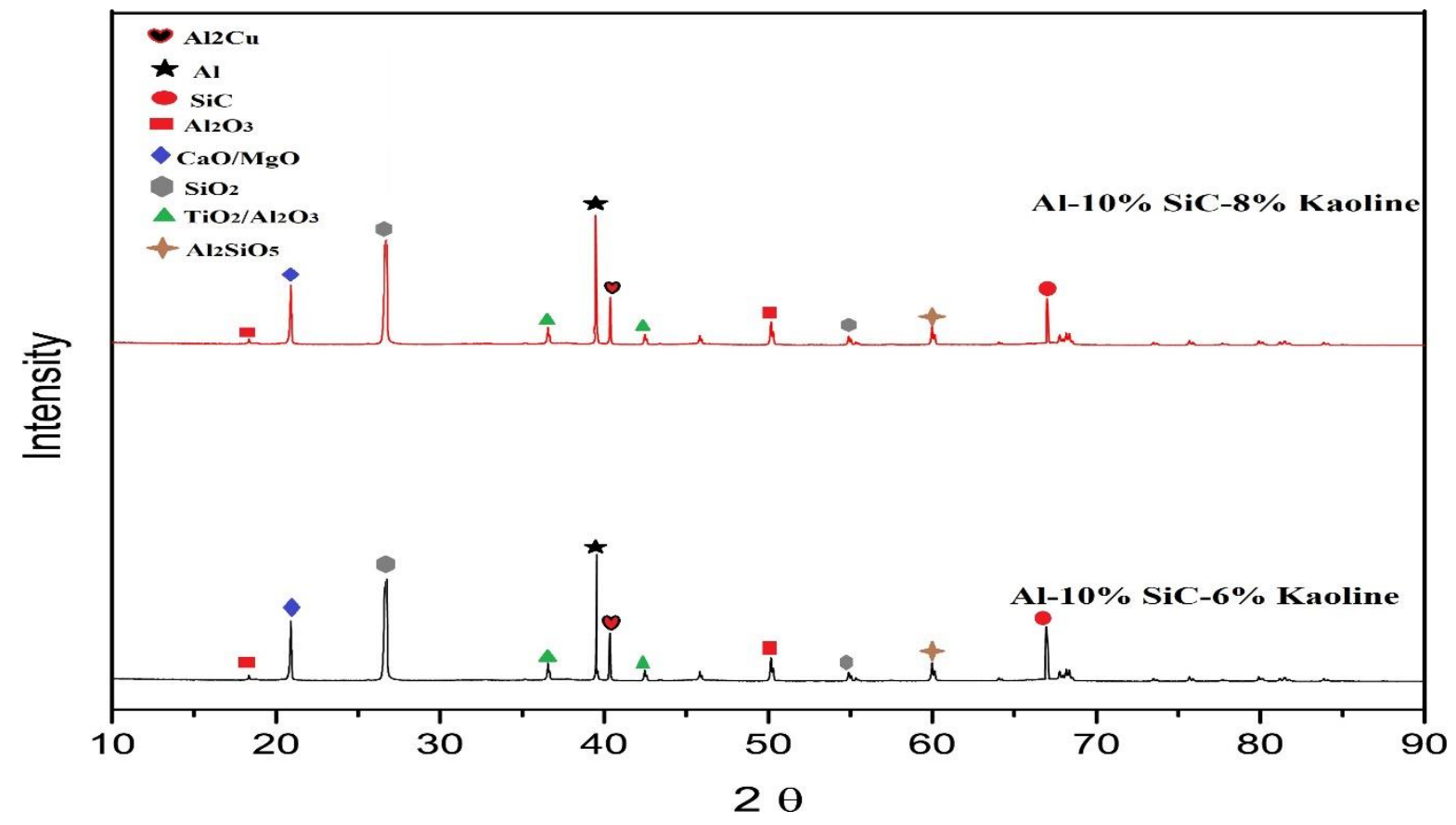

Fig. 5 XRD patterns for fabricated samples

\subsubsection{SEM analysis of fabricated HMMC}

Scanning Electron Micrograph images for fabricated composites was shown in Fig. 6 (a-d). Fig. 6 (a,b) depicts the uniform distribution of reinforcements and no clusters were identified for the samples having Al-10\% SiC-2\% Kaoline and Al-10\% SiC$4 \%$ Kaoline. The incorporation of kaoline reinforcements of more than $4 \%$ causes the formation of agglomerations and clusters of $\mathrm{Al}_{2} \mathrm{Cu}$ which was identified in Fig. $6(\mathrm{c}, \mathrm{d})$ and the corresponding peaks shown in XRD pattern of Fig. (5). The obtained peaks for $\mathrm{Al}_{2} \mathrm{Cu}$ cluster was similar to Shakie et al., [21]. The existence of thermal mismatch between the agglomerations and reinforcements leads to decreases the bonding strength and the load-bearing capability of the composite. This, in turn, leads to the degradation of the strength of the composite $[6,25]$. The SEM micrographs of all composite samples (Fig. 6 (a-d)) infers that the samples are free from voids and pores, which signifies that the samples were not undergone any oxidation during sintering and are free from defects. Fig. 7(b) represents the SEM 
image for $\mathrm{SiC}$ and the corresponding $\mathrm{Si}$ and $\mathrm{C}$ peaks were identified in $\mathrm{EDX}$, Confirms the presence of $\mathrm{SiC}$ in the Al-SiC-Kaoline composite. Fig. 7 (c) Depicts the existence of $\mathrm{Al}$. Si, Fe, $\mathrm{O}, \mathrm{Cu}, \mathrm{Zn}, \mathrm{Mn}$ peaks, indicates the presence of Kaoline in the fabricated composite. The existence of strong interfacial between the Aluminium matrix and reinforcements was depicted in EDS mapping as shown in Fig. 8. The existence and uniform distribution of elements such as oxygen $(\mathrm{O})$, magnesium (Mg), Iron (Fe), Carbon( C), Silicon ( $\mathrm{Si}$ ), Aluminium (Al) were found in EDS mapping as shown in Fig. 8. The presence of these elements confirms the presence of $\mathrm{SiO}_{2}, \mathrm{Al}_{2} \mathrm{O}_{3}, \mathrm{MgO}$, and $\mathrm{Fe} 2 \mathrm{O} 3$ which are the main constituents that are found in kaoline reinforcement.
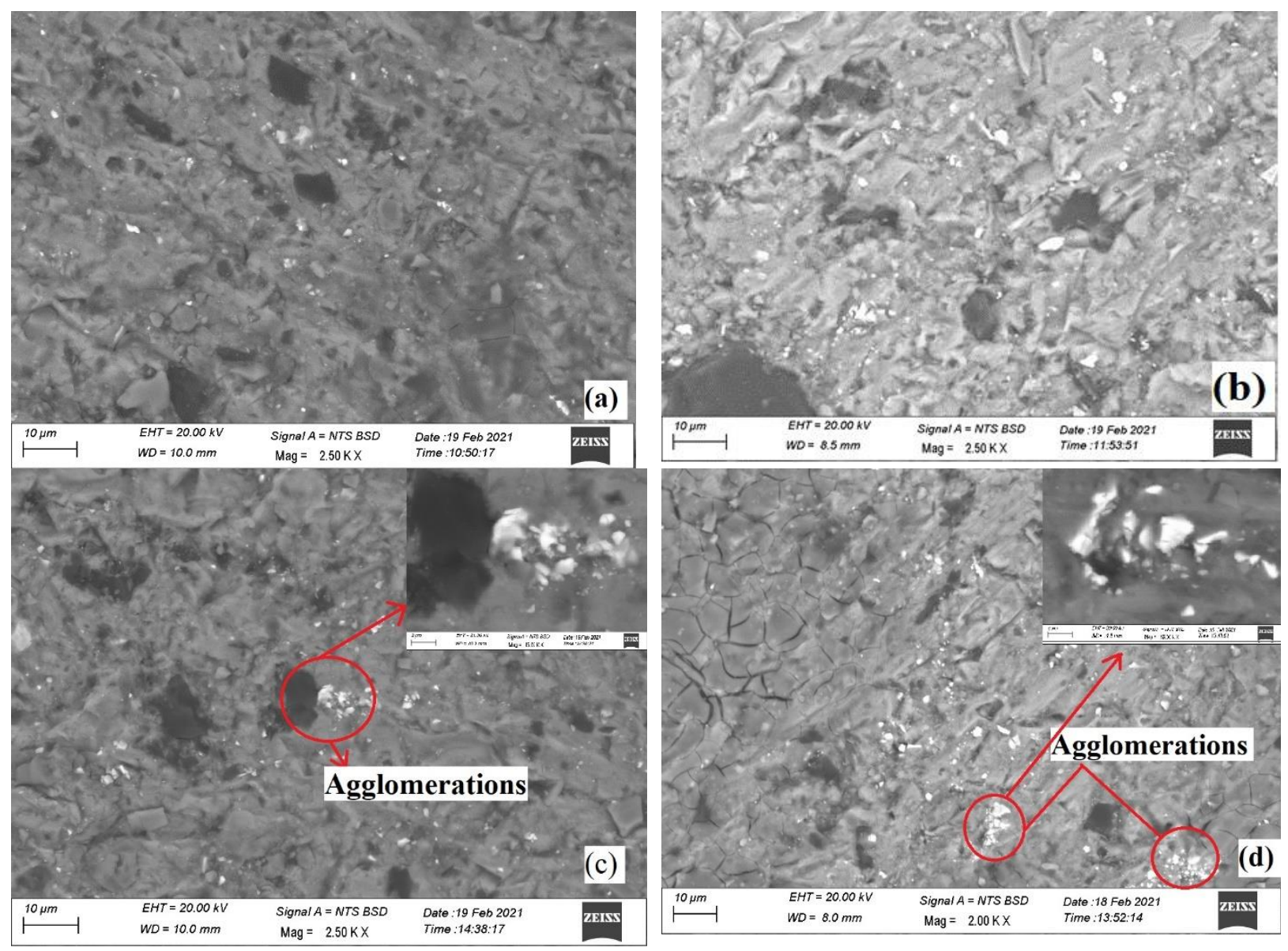

Fig. 6 SEM micrographs for (a) Al-10\% SiC-2\% kaoline, (b) Al-10\% SiC-4\% kaoline, (c) Al-10\% SiC-6\% kaoline, (d) Al-10\% SiC-8\% kaoline 

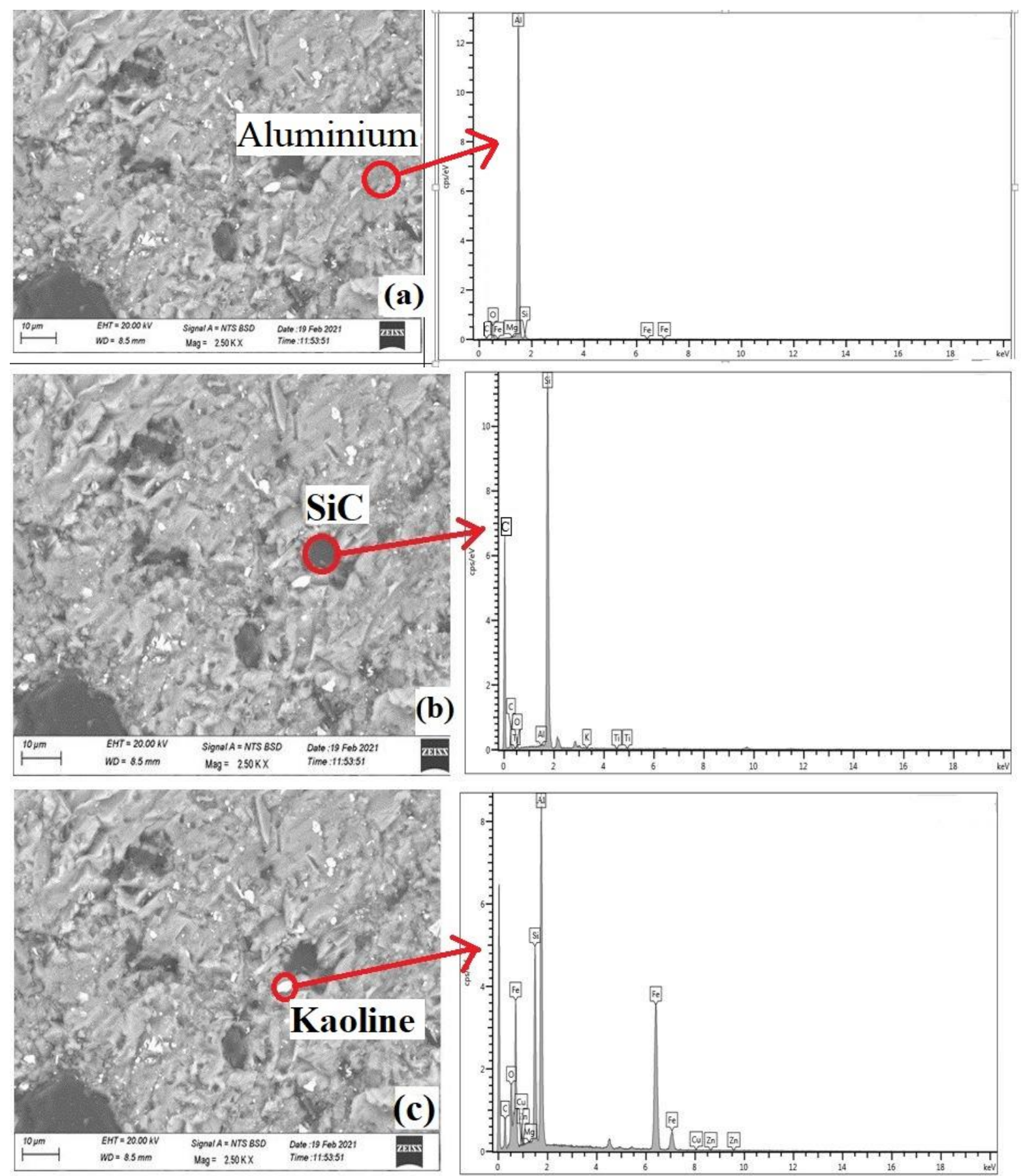

Fig. 7 SEM and corresponding EDX pattern for (a) matrix Al, (b) SiC reinforcement, (c) Kaoline reinforcement in fabricated composite sample 
EDS Layered Image 2

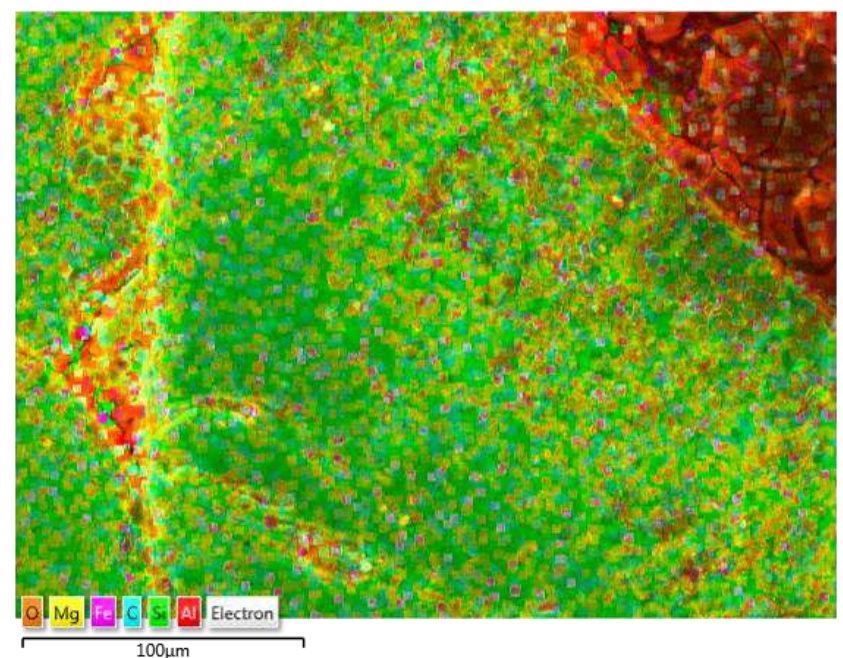

Si K $\alpha 1$

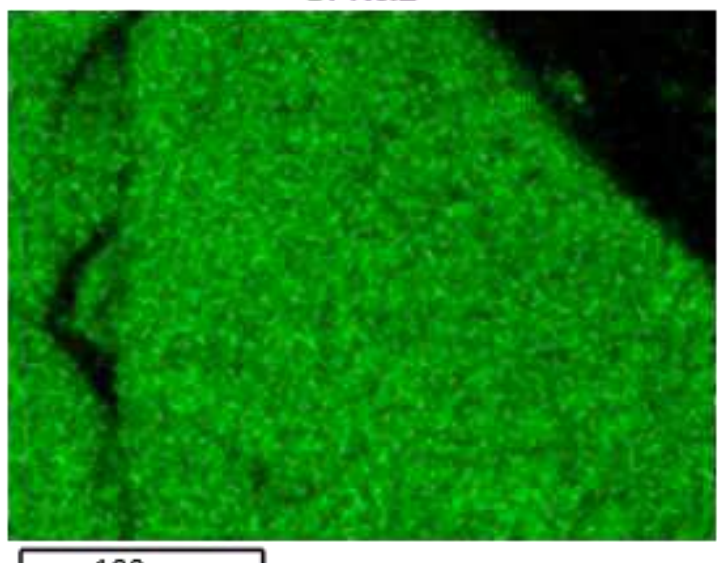

$100 \mu \mathrm{m}$

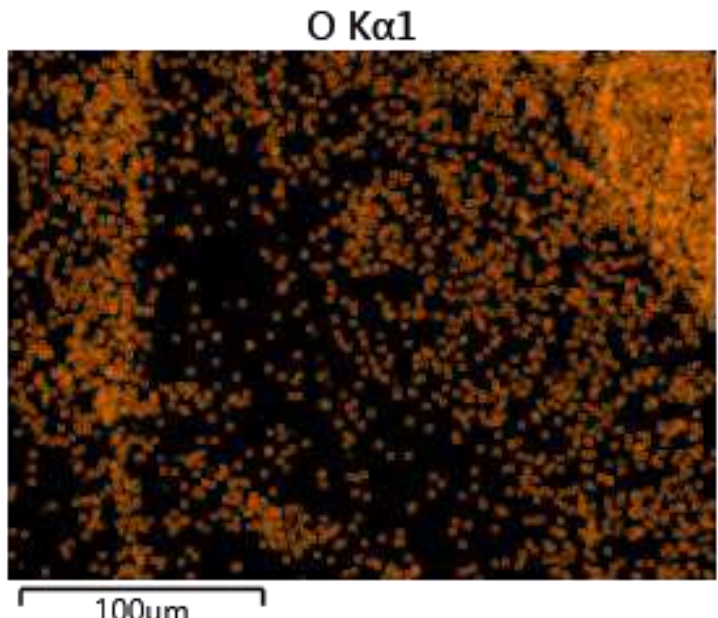

Al Ka1

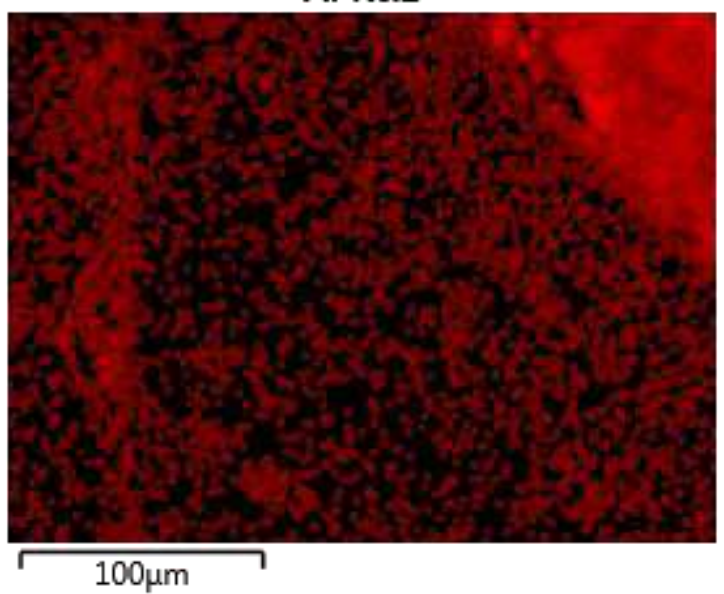

\section{K $\alpha 1 \_2$}

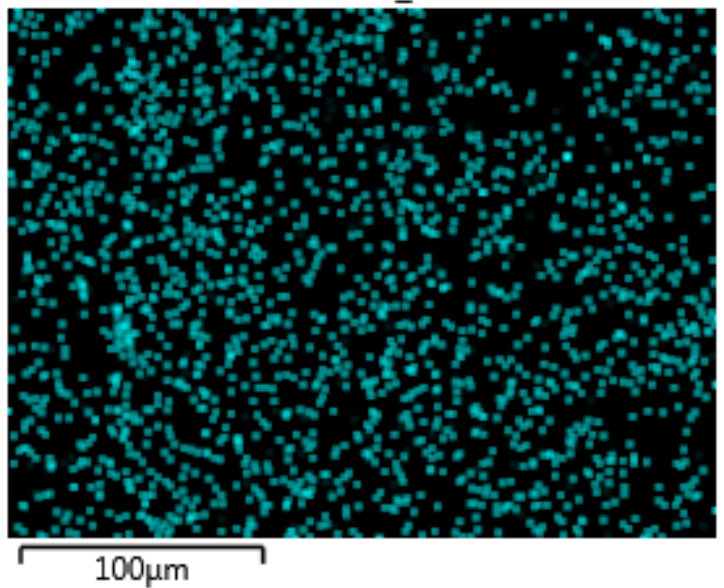


$\mathrm{Mg} \mathrm{K} \alpha 1 \_2$

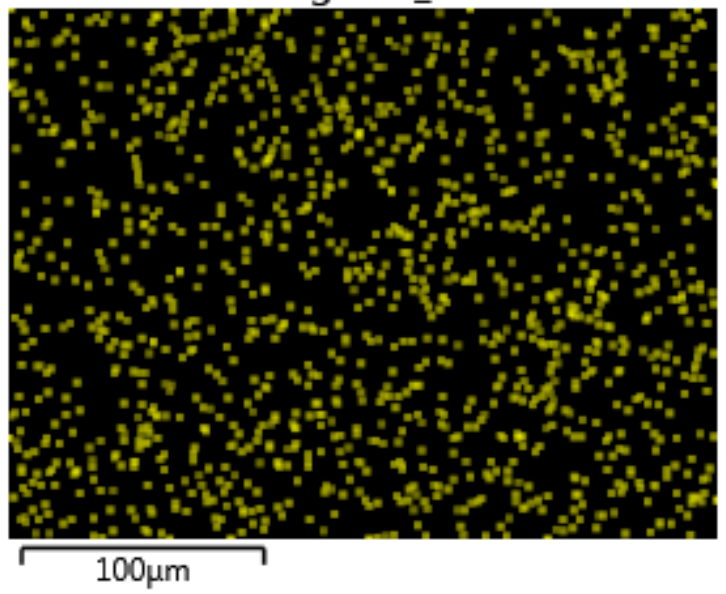

$\mathrm{Fe} \mathrm{K} \alpha 1$

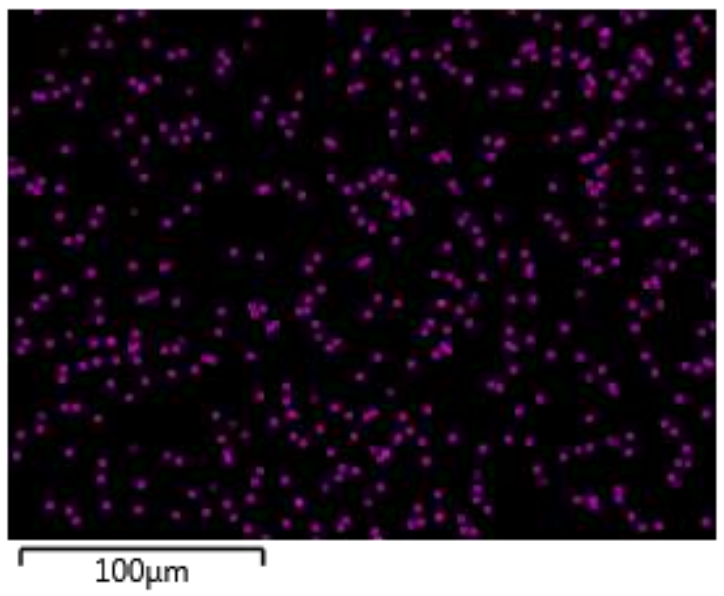

Fig. 8 EDS mapping for the matrix and reinforcement interface

\subsection{Physical Characterization of fabricated HMMC}

\subsubsection{Influence of reinforcement particles on Density and porosity of Hybrid AMMC}

The effect of SiC and Kaoline on the density of hybrid Aluminium MMC is shown in Fig. 9. The theoretical density of the composite decreases from $2.71 \mathrm{~g} / \mathrm{cc}$ for unreinforced Aluminium to $2.7552 \mathrm{~g} / \mathrm{cc}$ for $\mathrm{Al}-10 \% \mathrm{SiC}-8 \%$ Kaoline. The experimental densities decline from $2.6706 \mathrm{~g} / \mathrm{cc}$ for unreinforced Aluminium to $2.7151 \mathrm{~g} / \mathrm{cc}$ for Al- $10 \% \mathrm{SiC}-8 \%$ Kaoline. This decrement in density is due to the lower density of Kaoline $(2.65 \mathrm{~g} / \mathrm{cc})$ against the density of $\mathrm{SiC}(3.21 \mathrm{~g} / \mathrm{cc})$ and density of Aluminium $(2.71 \mathrm{~g} / \mathrm{cc})$. As the melting temperature of $\mathrm{SiC}$ reinforcement $\left(2730^{\circ} \mathrm{C}\right)$ much higher than that of kaoline $\left(740^{\circ} \mathrm{C}\right)$, These $\mathrm{SiC}$ reinforcements were not properly sintered at the sintering temperature $\left(620^{\circ} \mathrm{C}\right)$ and acts as diffusion barriers could be the reason for the decrement in relative density of Hybrid composite [26]. The obtained experimental density values are close to the theoretical density which shows the porosity defects are less in the fabricating sample and the maximum porosity of $1.455 \%$ was obtained at $\mathrm{Al}-10 \%$ SiC- $8 \%$ Kaoline (shown in Fig. 10). This was attributed due to the formation of oxides and gas entrapment during the sintering of composite[27]. In addition to this, at $8 \%$ of kaoline 
reinforcement, more number of kaoline particles undergone sintering and chances of formation of oxides of $\mathrm{Si}, \mathrm{Al}$ and $\mathrm{Ca}$. These oxides weaken the interfacial bonding between the matrix and reinforcement particles. As the kaoline contains oxides of $\mathrm{Al}, \mathrm{Si}, \mathrm{Ca}, \mathrm{Ti}$, these particles may undergo oxidation during sintering. Moreover, these oxides enhance the contact region between the matrix and reinforcement particles enhances, thereby the presence of void content in the material increases[2729].

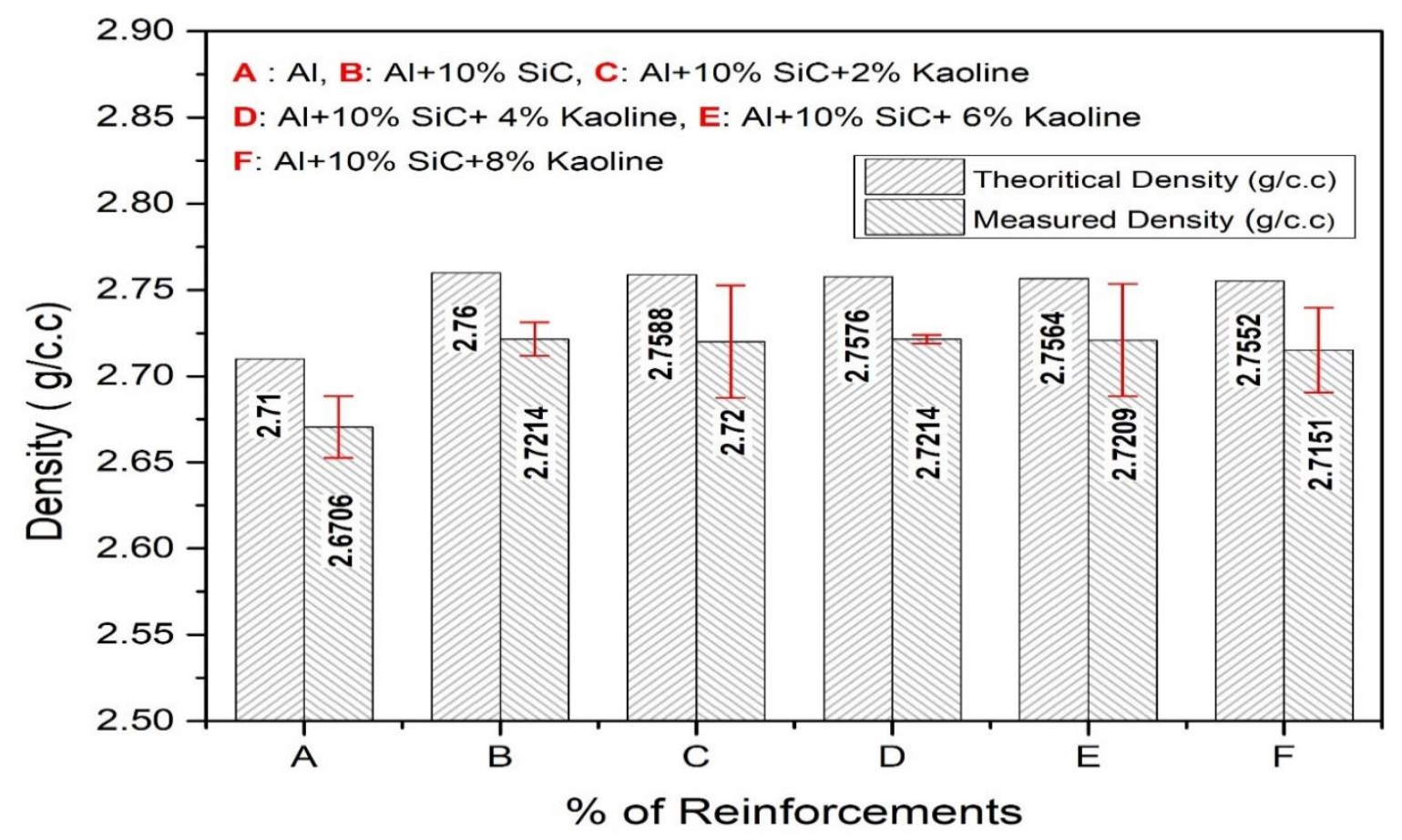

Fig. 9 Variation of Density of HMMC with \% reinforcement 


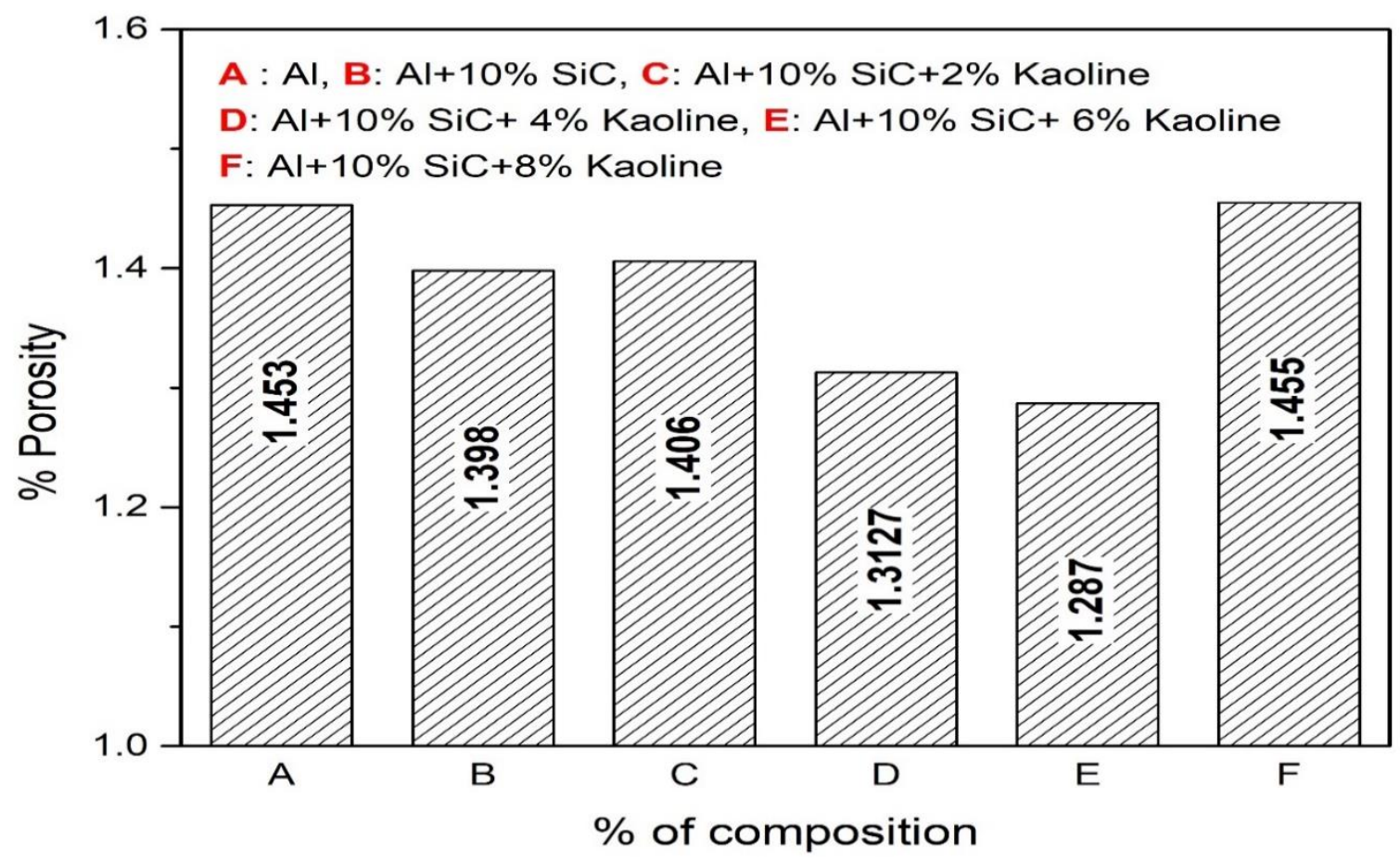

Fig. 10 Variation of \% Porosity of HMMC with \% reinforcement

\subsection{Mechanical Properties}

\subsubsection{Influence of reinforcement particles on Hardness of Hybrid HAMMC}

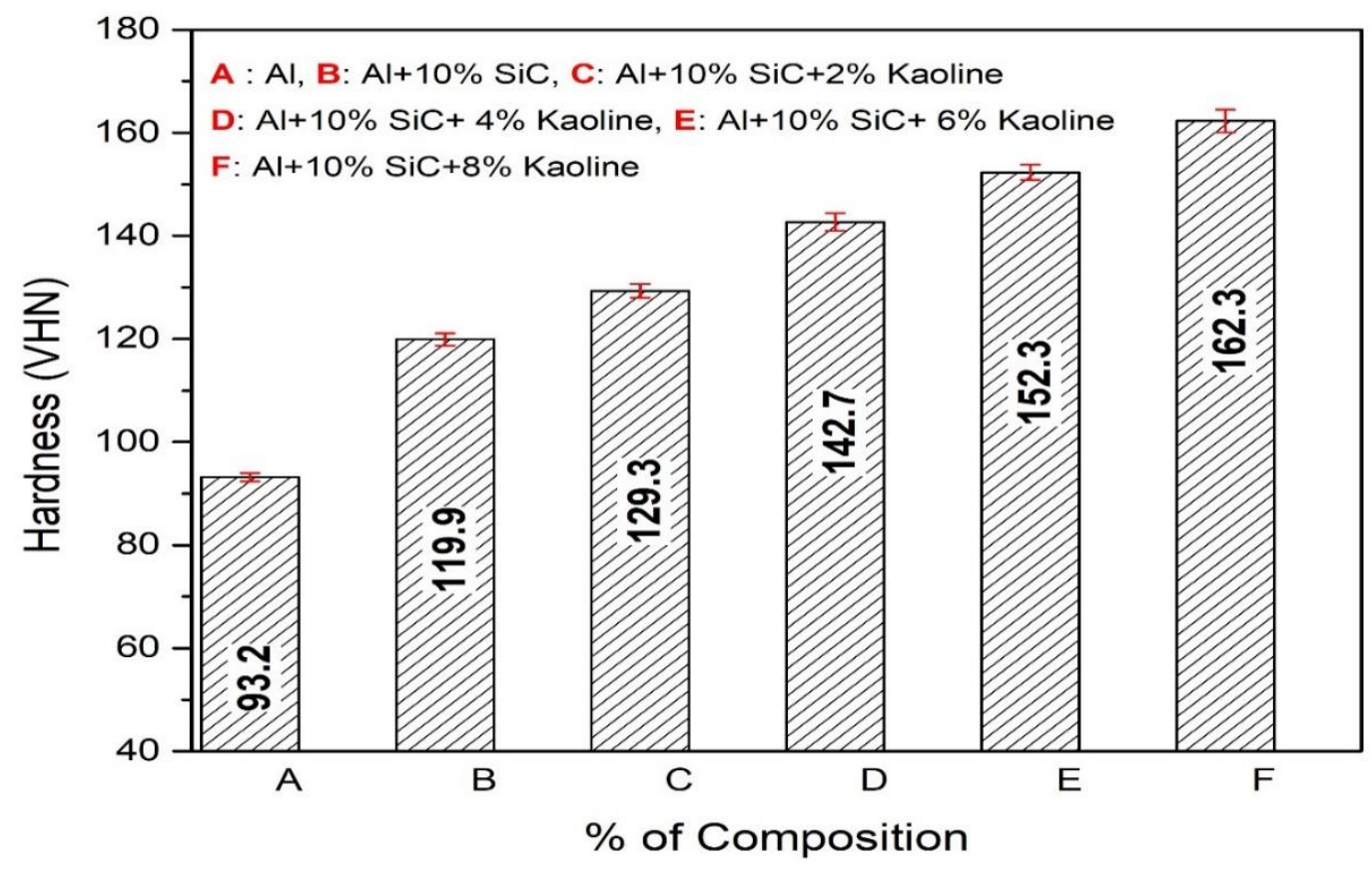

Fig. 11 Variation of Hardness of HMMC with \% reinforcement 
The micro-Vickers hardness test on the polished specimen was conducted by applying a load of $25 \mathrm{~N}$. Fig. 11 represents the effect of reinforcement on the hardness of hybrid MMC. It was found that the hardness of the Hybrid MMC increases from 93.2 $\mathrm{VHN}$ (unreinforced $\mathrm{Al}$ ) to $162.3 \mathrm{VHN}$ (Al-10\% SiC-8\% Kaoline), indicating an improvement of $74.1 \%$ hardness than unreinforced Aluminium. The increment in hardness was attributed due to several reasons. Firstly, the Incorporation of harder and stiffer $\mathrm{SiC}$ and kaoline (contains $\mathrm{Al}_{2} \mathrm{O}_{3}, \mathrm{SiO}_{2}$ ) into the softer aluminium matrix and the uniform distribution of reinforcements in the matrix material considerably enhances the hardness of the composite compared to the unreinforced aluminium sample. Secondly, the incorporation of harder hybrid reinforcements improves the dislocation density which hinders the movement of dislocations during the indentation [30]. Lastly, The presence of Magnesium in the kaoline reinforcement enhances the wettability at the interfaces of matrix and reinforcement particles, which in turn improves the load transfer from softer

aluminium to harder reinforcements during the indentation test, resulting in improvement in hardness of the composite[31].

\subsubsection{Influence of reinforcement particles on Ultimate Tensile strength and Yield Strength of HAMMC}




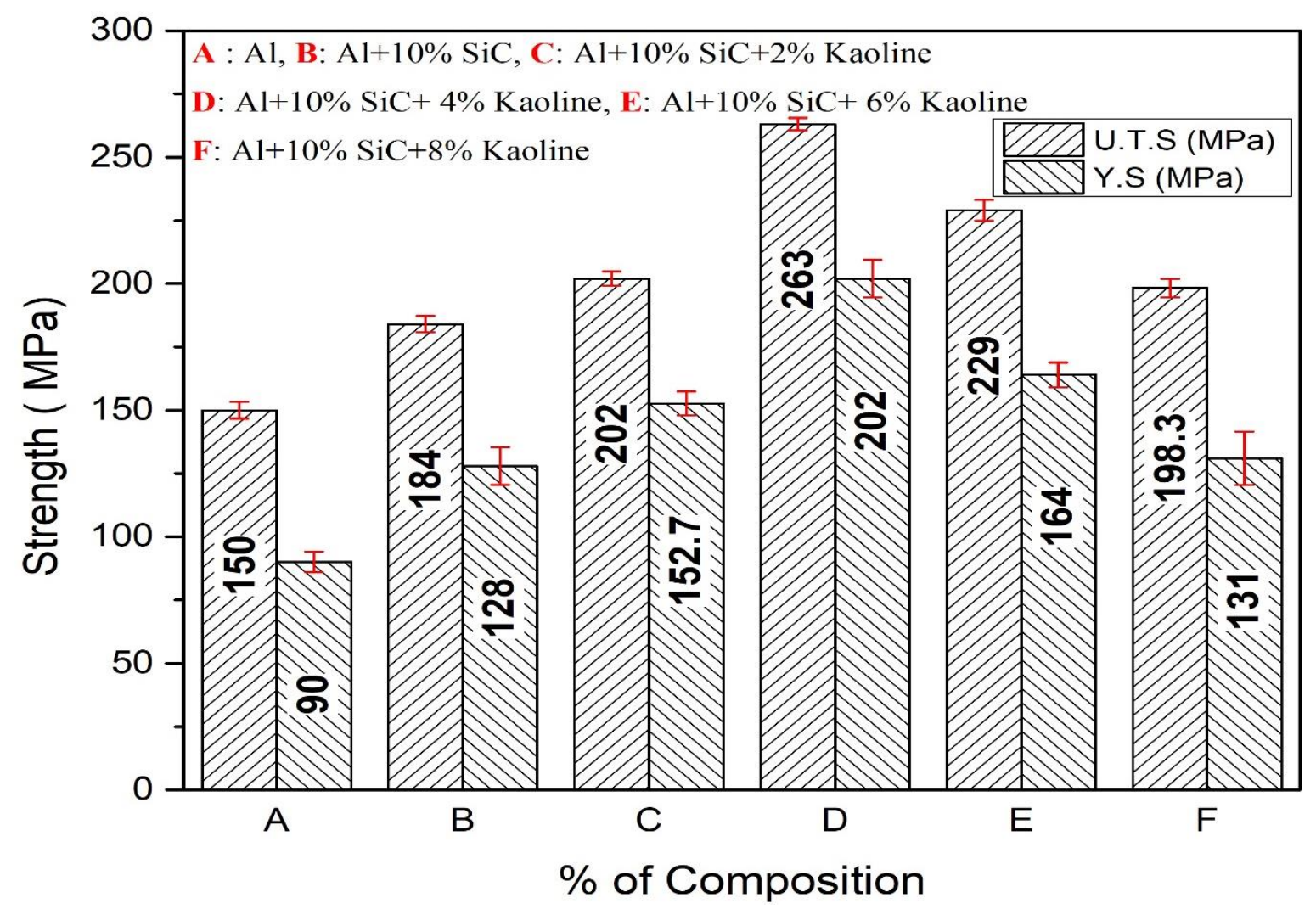

Fig. 12 Variation of U.T.S and Y.S of HMMC with \% reinforcement

Fig. 12 represents the average ultimate strength and average yield strength of the fabricated hybrid composite samples. It can be observed that the U.T.S and Yield strength of the composite considerably increased by $75.33 \%$ and $124 \%$ respectively up to the addition of $10 \% \mathrm{SiC}$ and $4 \%$ kaoline reinforcements when compared to unreinforced aluminium. The maximum value of U.T.S and Yield strength is 263 $\mathrm{MPa}$ and $202 \mathrm{MPa}$ respectively for Al-10\% SiC-4\% Kaoline. Experimental results indicate that the incorporation of $\mathrm{SiC}$ and Kaoline reinforcements strengthen the softer aluminium matrix. The difference in the coefficient of thermal expansion of softer aluminium matrix and harder ceramic reinforcements creates strain fields around the reinforcement particles during sintering. These strain fields impede the motion of dislocations during tensile load and the higher tensile load must be applied to move the dislocations around the strain field which improves the U.T.S and Yield 
strength of the composite[32]. In addition to this, uniform distribution of reinforcements facilitates strong interfacial bonding between matrix-reinforcements offers resistance to dislocation movement which improves the strength of the composite up to $4 \%$ Kaoline reinforcement [33]. However, The Addition of kaoline reinforcement beyond $4 \%$ leads to decreases in the U.T.S from $263 \mathrm{MPa}$ to 198.3 $\mathrm{MPa}$ and yield strength from $202 \mathrm{MPa}$ to $131 \mathrm{MPa}$ for $4 \%$ kaoline to $8 \%$ kaoline reinforcement. This was attributed to the fact that the incorporation of a higher volume fraction of harder reinforcements tends to improve the slip planes. During application of tensile load, the atoms present along the slip planes can easily find the path for movement along these slip planes and at the lower applied loads, the plastic deformation of material takes place. Similar results are reported by Sudarshan and surappa for different percentage of fly ash reinforcements [34]. The ratio of Yield Strength to U.T.S was found to be 0.76 . It can be clear that the early stage yielding and strain hardening occurs in the composite material. Hence the fabricated composite is suitable for fabricating Metal forming related operations.

\subsubsection{Influence of reinforcement particles on the Impact strength of HMMC.}




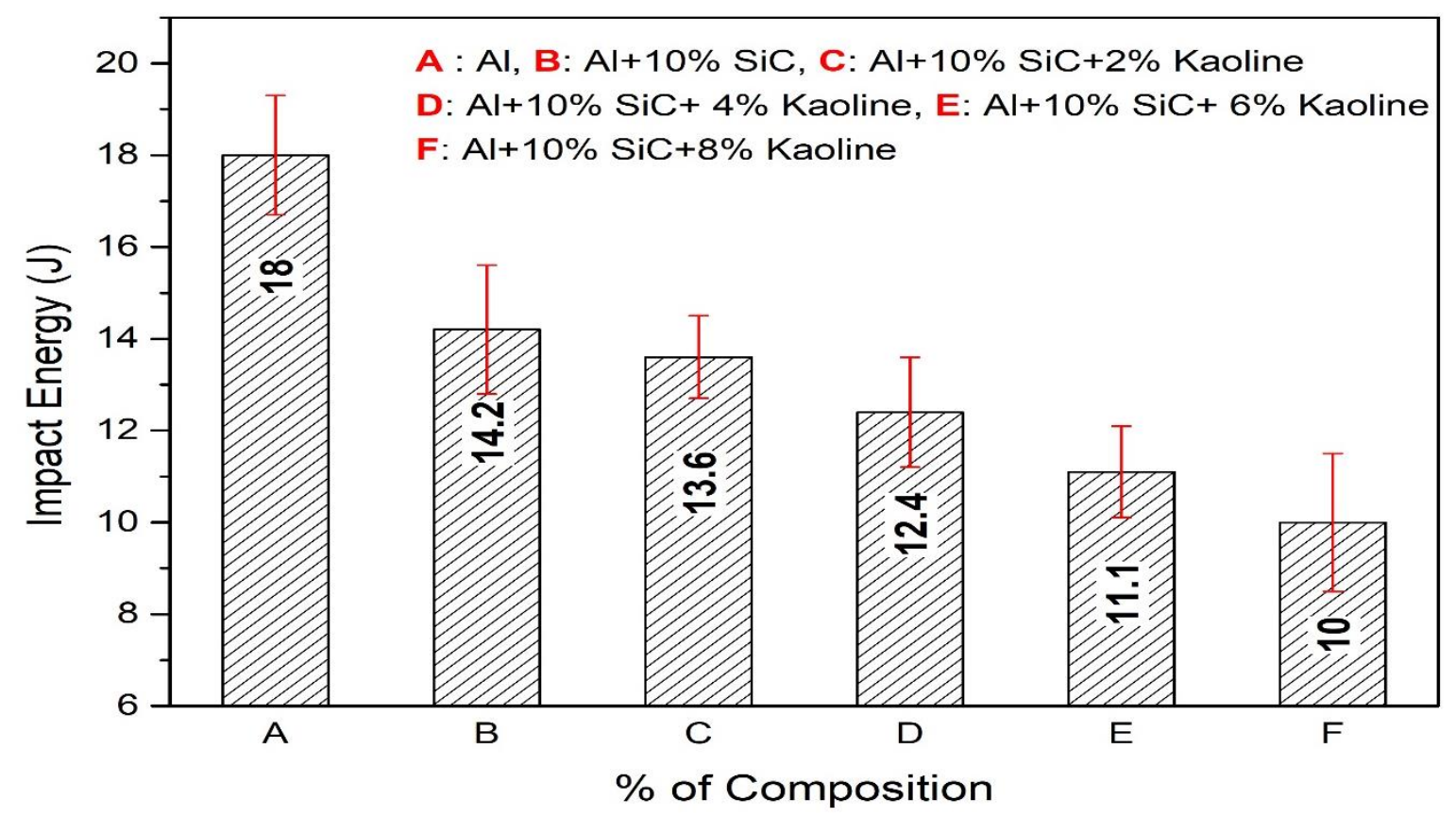

Fig. 13 Variation of Impact energy of HMMC with \% reinforcement

The influence of kaoline and $\mathrm{SiC}$ reinforcements on the impact strength of HAMMC is shown in Fig. 13. The impact strength of hybrid composite found to be decreased with the increase in Kaoline reinforcement particles. The impact strength is higher for unreinforced Aluminium compared to composite with $10 \% \mathrm{SiC}$ and $8 \%$ Kaoline reinforcement. The impact strength was decreased from $18 \mathrm{~J}$ for unreinforced Aluminium to $10 \mathrm{~J}$ for $\mathrm{Al}-10 \% \mathrm{SiC}-8 \%$ Kaoline, i.e $44 \%$ decrement in impact strength observed from the base Aluminium alloy to Al-10\%SiC-8\%Kaoline composite. The impact energy of the specimen is due to the energy absorbed by the material before fracture. The higher impact of Aluminium was attributed due to the presence of higher ductility which tends to heavier plastic deformation before the fracturing at higher stress concentration areas. The presence of harder $\mathrm{SiC}$ and Kaoline reinforcements acts as barriers for dislocation movement which leads to improving the hardness and thereby decreases the plastic deformation energy of composite[35, 36]. 


\subsection{Fractography}

Fractography analysis was conducted on fractured tensile specimens to know the type of fracture that occurred during the tensile test. In general, the mode of fracture in tensile specimens was categorized into the ductile and brittle fracture. The formation of clusters during the sintering and non-uniform distribution of reinforcements are the main factors that govern and influence the type of fracture in the specimens. Non-uniform distribution of reinforcements leads to the difference in strain carrying capacity between the Aluminium matrix and reinforcements which attribute to the initiation of the crack in the material [10,37]. Microvoid coalescence and Dimples was generally observed in ductile fractured samples due to necking that occurred in samples before the fracture occurs. But in the case of brittle materials, transgranular boundary movements and cleavages are formed due to lesser deformation energy. These movements enhance the crack through grain boundaries when the applied load exceeds the tensile strength of the material. Fig. 14 depicts the SEM images for the fractured tensile surface. Fig. 14(a) shows the fractured surface of unreinforced aluminium which shows the presence of dimples that indicates the ductile fracture with large plastic deformation and localized stresses[38]. Fig. 14 (b, c) shows the presence of shallower Dimples and microvoids which signifies that the composite failure occurs in ductile mode. Incorporation of kaoline reinforcements more than $2 \%$ improves the brittleness of the specimen due to the presence of more wt\% of oxides of $\mathrm{Al}, \mathrm{Si}$ and $\mathrm{Ti}$ in kaoline reinforcements leads to cleavage patterns on the fracture surface causing the brittle fracture in the composite specimens as shown in Fig. 14(d-f). The presence of harder $\mathrm{SiC}$ and Kaoline reinforcements in the matrix reduces the elastic deformation in the matrix which attributes to debonding and clustering of reinforcement particles from softer ductile matrix causes microcracks during application of tensile load. 

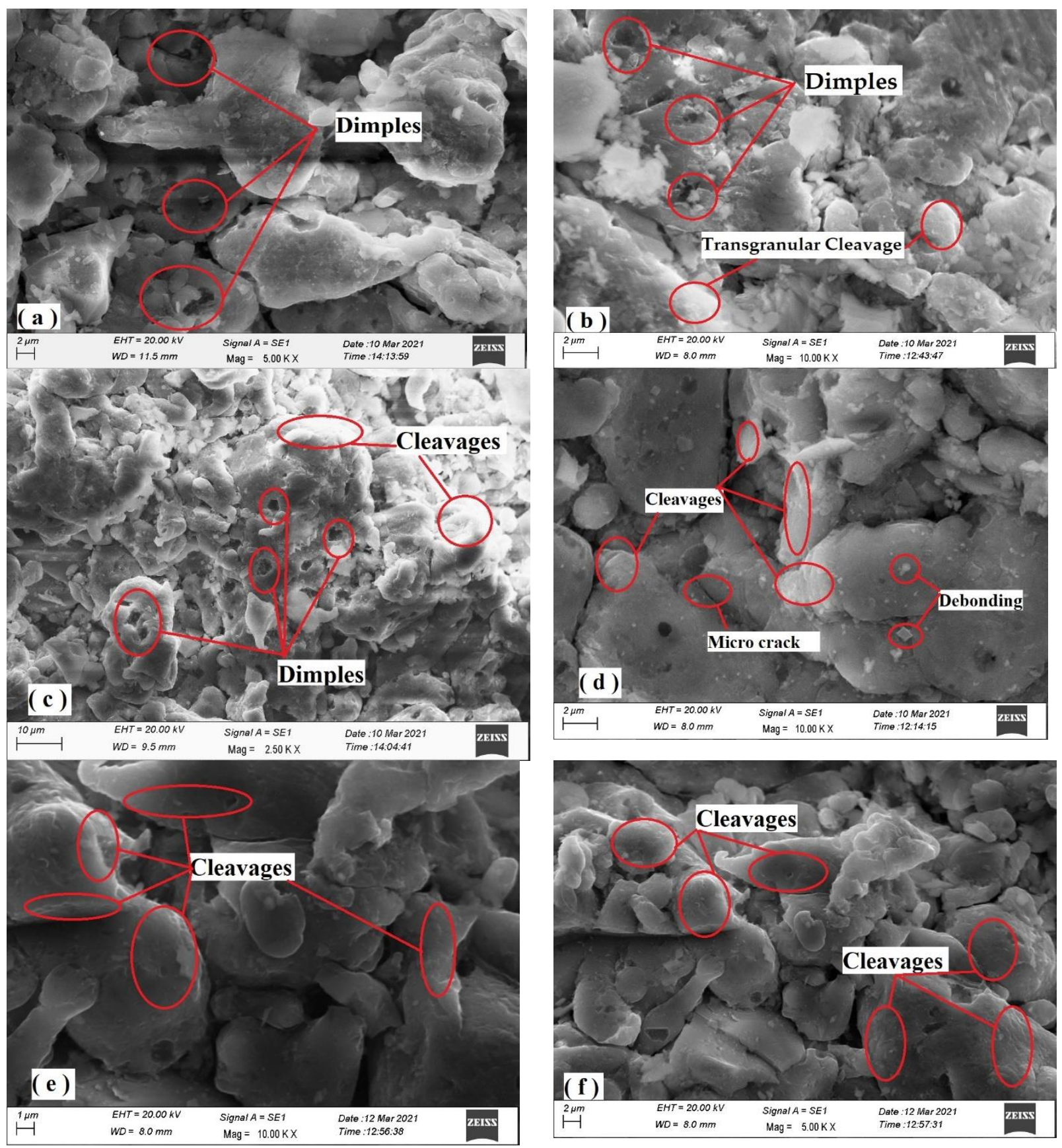

Fig. 14 Fractured surface for (a) unreinforced Al, (b) Al-10\% SiC, (c) Al-10\% SiC-2\% Kaoline, (d) Al-10\% SiC-4\% Kaoline, (e) Al-10\% SiC-6\% Kaoline, (f) Al-10\% SiC-8\% Kaoline 


\section{Conclusions}

Following conclusions are drawn on the Al-SiC-Kaoline hybrid metal matrix composite fabricated through powder metallurgy technique.

- XRD peaks reveal the presence of $\mathrm{SiC}$ and Kaoline reinforcements in the fabricated samples. In addition to this, the existence of intermetallic compound such as $\mathrm{Al}_{2} \mathrm{Cu}$ peak was observed in $\mathrm{Al}-10 \%$ SiC-6\% Kaoline and Al-10\% SiC- 8\% Kaoline composite samples.

- The density of fabricated samples found to be decreased with increasing with kaoline reinforcement. The maximum porosity value of 1.455 was found for Al-10\% SiC-8\% Kaoline, which signifies that the fabricated samples are absence of pores and defects.

- The hardness of the composite found to be increased with increasing the kaoline reinforcement percentage. There was a $74.14 \%$ enhancement in Vickers hardness value for $\mathrm{Al}-10 \% \mathrm{SiC}-8 \%$ Kaoline than the unreinforced aluminium specimen.

- $75.3 \%$ enhancement in U.T.S and $124.4 \%$ enhancement in Yield strength of the composite was found up to the incorporation of $4 \%$ kaoline reinforcement. The addition of kaoline reinforcement above $4 \%$ leads to decrement in both U.T.S and Yield strength.

- Impact strength of fabricated composites found to be decreased with increasing the kaoline reinforcement.

- Fractography analysis revealed that the ductile fracture in $\mathrm{Al}, \mathrm{Al}-10 \% \mathrm{SiC}$, Al-10\% SiC-2\% Kaoline due to the formation of dimples. The incorporation of kaoline reinforcement of more than $4 \%$ improves the brittleness of the composite which in turn causes brittle fracture in remaining composite samples.

Acknowledgements Authors like to thank Central Instrumentation Facility at National Institute of Technology Silchar for XRD analysis. The authors also would like to appreciate the Advance center for Material Science at Indian Institute of Technology Kanpur for SEM and EDS analysis.

\section{Author's Contribution}

V.S.S Venkatesh carried out the fabrication, Mechanical characterization of composite samples and Drafted the initial version of manuscript. Ashish B 
Deoghare Reviewed and Edited the prepared manuscript. All authors read and approved the final manuscript.

\section{Data Availability}

Authors confirm that the entire data obtained during the Experiment was included in this available manuscript.

Compliance with Ethical Standards The Authors declare that they don't have known personal relationships or competing financial interest that could have appeared to influence the work reported in this manuscript.

\section{Conflict of interest}

Authors declared that they have no conflict of interest.

\section{Consent to Participate}

All the Authors are happily agreed to contribute in this research work.

\section{Consent of Publication}

Consent was obtained from all authors to publish this manuscript. All the authors read and approved this manuscript to publish this article.

\section{Funding Statement Not applicable.}

\section{References}

1. Liu S, Wang Y, Muthuramalingam T, Anbuchezhiyan G (2019) Effect of B4C and MOS2 reinforcement on micro structure and wear properties of aluminum hybrid composite for automotive applications. Compos. Part B Eng. 176

2. Manikandan R, Arjunan T V., Akhil AR (2020) Studies on micro structural characteristics, mechanical and tribological behaviours of boron carbide and cow dung ash reinforced aluminium (Al 7075) hybrid metal matrix composite. Compos Part B Eng 183:107668. https://doi.org/10.1016/j.compositesb.2019.107668

3. Ghosh S, Sahoo P, Sutradhar G (2012) Wear Behaviour of Al-SiCp Metal Matrix Composites and Optimization Using Taguchi Method and Grey Relational Analysis. J Miner Mater Charact Eng 11:1085-1094. https://doi.org/10.4236/jmmce.2012.1111115

4. Manoj M, Jinu GR, Muthuramalingam T (2018) Multi Response Optimization of AWJM Process Parameters on Machining TiB2 Particles Reinforced Al7075 Composite Using Taguchi-DEAR Methodology. Silicon 10:2287-2293. https://doi.org/10.1007/s12633-0189763-x

5. Kumar PN, Rajadurai A, Muthuramalingam T (2018) Multi-Response Optimization on Mechanical Properties of Silica Fly Ash Filled Polyester Composites Using Taguchi-Grey 
Relational Analysis. Silicon 10:1723-1729. https://doi.org/10.1007/s12633-017-9660-8

6. Ravi Kumar K, Kiran K, Sreebalaji VS (2017) Micro structural characteristics and mechanical behaviour of aluminium matrix composites reinforced with titanium carbide. J Alloys Compd 723:795-801. https://doi.org/10.1016/j.jallcom.2017.06.309

7. Ravikumar K, Kiran K, Sreebalaji VS (2017) Characterization of mechanical properties of aluminium/tungsten carbide composites. Measurement 102:142-149. https://doi.org/https://doi.org/10.1016/j.measurement.2017.01.045

8. Uyyuru RK, Surappa MK, Brusethaug S (2007) Tribological behavior of Al-Si-SiCp composites/automobile brake pad system under dry sliding conditions. Tribol Int 40:365373. https://doi.org/10.1016/j.triboint.2005.10.012

9. Rao VR, Ramanaiah N, Sarcar MMM (2016) Tribological properties of Aluminium Metal Matrix Composites (AA7075 Reinforced with Titanium Carbide (TiC) Particles). Int J Adv Sci Technol 88:13-26. https://doi.org/10.14257/ijast.2016.88.02

10. Baradeswaran A, Elayaperumal A, Franklin Issac R (2013) A statistical analysis of optimization of wear behaviour of Al- $\mathrm{Al} 2 \mathrm{O} 3$ composites using taguchi technique. Procedia Eng. 64:973-982

11. Radhika N, Raghu R (2017) Investigation on Mechanical Properties and Analysis of Dry Sliding Wear Behavior of Al LM13/AlN Metal Matrix Composite Based on Taguchi's Technique. J Tribol 139:. https://doi.org/10.1115/1.4035155

12. Bhandakkar A, Prasad RC, Sastry SML (2014) Fracture Toughness of AA2024 Aluminum Fly Ash Metal Matrix Composites. Int J 4:108-124. https://doi.org/10.5923/j.cmaterials.20140402.10

13. Sulaiman S, Marjom Z, Ismail MIS, et al (2017) Effect of Modifier on Mechanical Properties of Aluminium Silicon Carbide (Al-SiC) Composites. Procedia Eng 184:773-777. https://doi.org/10.1016/j.proeng.2017.04.156

14. Sarkar S, Bhirangi A, Mathew J, et al (2018) Fabrication characteristics and mechanical behavior of Rice Husk Ash-Silicon Carbide reinforced Al-6061 alloy matrix hybrid composite. Mater Today Proc 5:12706-12718. https://doi.org/10.1016/j.matpr.2018.02.254

15. Alaneme KK, Adewale TM, Olubambi PA (2014) Corrosion and wear behaviour of Al-Mg$\mathrm{Si}$ alloy matrix hybrid composites reinforced with rice husk ash and silicon carbide. J Mater Res Technol 3:9-16. https://doi.org/10.1016/j.jmrt.2013.10.008

16. Rajmohan T, Palanikumar K, Ranganathan S (2013) Evaluation of mechanical and wear properties of hybrid aluminium matrix composites. Trans Nonferrous Met Soc China (English Ed 23:2509-2517. https://doi.org/10.1016/S1003-6326(13)62762-4

17. Fatile OB, AkinruliI J fedayo, Amori AA (2014) Microstructure and Mechanical Behaviour of Stir-Cast Al-Mg-Sl Alloy Matrix Hybrid Composite Reinforced with Corn Cob Ash and Silicon Carbide. Int J Eng Technol Innov 4:251-259

18. Manohar G, Pandey KM, Maity SR (2021) Effect of sintering mechanisms on mechanical properties of AA7075/B4C composite fabricated by powder metallurgy techniques. Ceram 
Int. https://doi.org/https://doi.org/10.1016/j.ceramint.2021.02.073

19. Toptan F, Kilicarslan A, Karaaslan A, et al (2010) Processing and microstructural characterisation of AA 1070 and AA 6063 matrix B4Cp reinforced composites. Mater Des 31:S87-S91. https://doi.org/10.1016/j.matdes.2009.11.064

20. Ramadoss N, Pazhanivel K, Anbuchezhiyan G (2020) Synthesis of B4C and BN reinforced Al7075 hybrid composites using stir casting method. J Mater Res Technol 9:6297-6304. https://doi.org/10.1016/j.jmrt.2020.03.043

21. Gatea S, Ou H, McCartney G (2018) Deformation and fracture characteristics of Al6092/SiC/17.5p metal matrix composite sheets due to heat treatments. Mater Charact 142:365-376. https://doi.org/10.1016/j.matchar.2018.05.050

22. Liu R, Wu C, Zhang J, et al (2018) Microstructure and mechanical behaviors of the ultrafine grained AA7075/B4C composites synthesized via one-step consolidation. J Alloys Compd 748:737-744. https://doi.org/10.1016/j.jallcom.2018.03.152

23. Viala JC, Bouix J, Gonzalez G, Esnouf C (1997) Chemical reactivity of aluminium with boron carbide. J Mater Sci 32:4559-4573. https://doi.org/10.1023/A:1018625402103

24. Zhang L, Shi G, Xu K, et al (2020) Phase transformation and mechanical properties of B4C/Al composites. J Mater Res Technol 9:2116-2126. https://doi.org/10.1016/j.jmrt.2019.12.042

25. Erdemir F, Canakci A, Varol T (2015) Microstructural characterization and mechanical properties of functionally graded $\mathrm{Al} 2024 / \mathrm{SiC}$ composites prepared by powder metallurgy techniques. Trans Nonferrous Met Soc China (English Ed 25:3569-3577. https://doi.org/10.1016/S1003-6326(15)63996-6

26. ROUHI M, MOAZAMI-GOUDARZI M, ARDESTANI M (2019) Comparison of effect of $\mathrm{SiC}$ and $\mathrm{MoS} 2$ on wear behavior of Al matrix composites. Trans. Nonferrous Met. Soc. China (English Ed. 29:1169-1183

27. Bhowmik A, Dey D, Biswas A (2020) Comparative Study of Microstructure, Physical and Mechanical Characterization of SiC/TiB2 Reinforced Aluminium Matrix Composite. Silicon. https://doi.org/10.1007/s12633-020-00591-2

28. Arunkumar S, Kumar AS (2021) Studies on Egg Shell and SiC Reinforced Hybrid Metal Matrix Composite for Tribological Applications. Silicon. https://doi.org/10.1007/s12633021-00965-0

29. Dey D, Biswas A (2020) Comparative Study of Physical, Mechanical and Tribological Properties of Al2024 Alloy and SiC-TiB2 Composites. Silicon. https://doi.org/10.1007/s12633-020-00560-9

30. Kumar CAV, Rajadurai JS (2016) Influence of rutile (TiO2) content on wear and microhardness characteristics of aluminium-based hybrid composites synthesized by powder metallurgy. Trans Nonferrous Met Soc China (English Ed 26:63-73. https://doi.org/10.1016/S1003-6326(16)64089-X

31. Zhang X, Zhang Z, Liu Y, et al (2019) High-performance B 4 C-TiB 2 -SiC composites 
with tuneable properties fabricated by reactive hot pressing. J Eur Ceram Soc 39:29953002. https://doi.org/10.1016/j.jeurceramsoc.2019.04.001

32. David Raja Selvam J, Robinson Smart DS, Dinaharan I (2013) Microstructure and some mechanical properties of fly ash particulate reinforced AA6061 aluminum alloy composites prepared by compocasting. Mater Des 49:28-34. https://doi.org/10.1016/j.matdes.2013.01.053

33. Michael Rajan HB, Ramabalan S, Dinaharan I, Vijay SJ (2013) Synthesis and characterization of in situ formed titanium diboride particulate reinforced AA7075 aluminum alloy cast composites. Mater Des 44:438-445. https://doi.org/10.1016/j.matdes.2012.08.008

34. Sudarshan, Surappa MK (2008) Synthesis of fly ash particle reinforced A356 Al composites and their characterization. Mater Sci Eng A 480:117-124. https://doi.org/10.1016/j.msea.2007.06.068

35. Sharma P, Sharma S, Khanduja D (2016) Effect of graphite reinforcement on physical and mechanical properties of aluminum metal matrix composites. Part Sci Technol 34:17-22. https://doi.org/10.1080/02726351.2015.1031924

36. Das D, Chakraborty V, Kumar Nanda B, Chandra Routara B (2018) Turning performance of $\mathrm{Al} 7075 / \mathrm{SiCp} \mathrm{MMC}$ and multi-response optimization using WPCA and Taguchi approach. Mater Today Proc 5:6030-6037. https://doi.org/10.1016/j.matpr.2017.12.207

37. Fadavi Boostani A, Tahamtan S, Jiang ZY, et al (2015) Enhanced tensile properties of aluminium matrix composites reinforced with graphene encapsulated $\mathrm{SiC}$ nanoparticles. Compos Part A Appl Sci Manuf 68:155-163. https://doi.org/10.1016/j.compositesa.2014.10.010

38. Pazhouhanfar Y, Eghbali B (2018) Microstructural characterization and mechanical properties of TiB2 reinforced Al6061 matrix composites produced using stir casting process. Mater Sci Eng A 710:172-180. https://doi.org/10.1016/j.msea.2017.10.087 


\section{Figures}

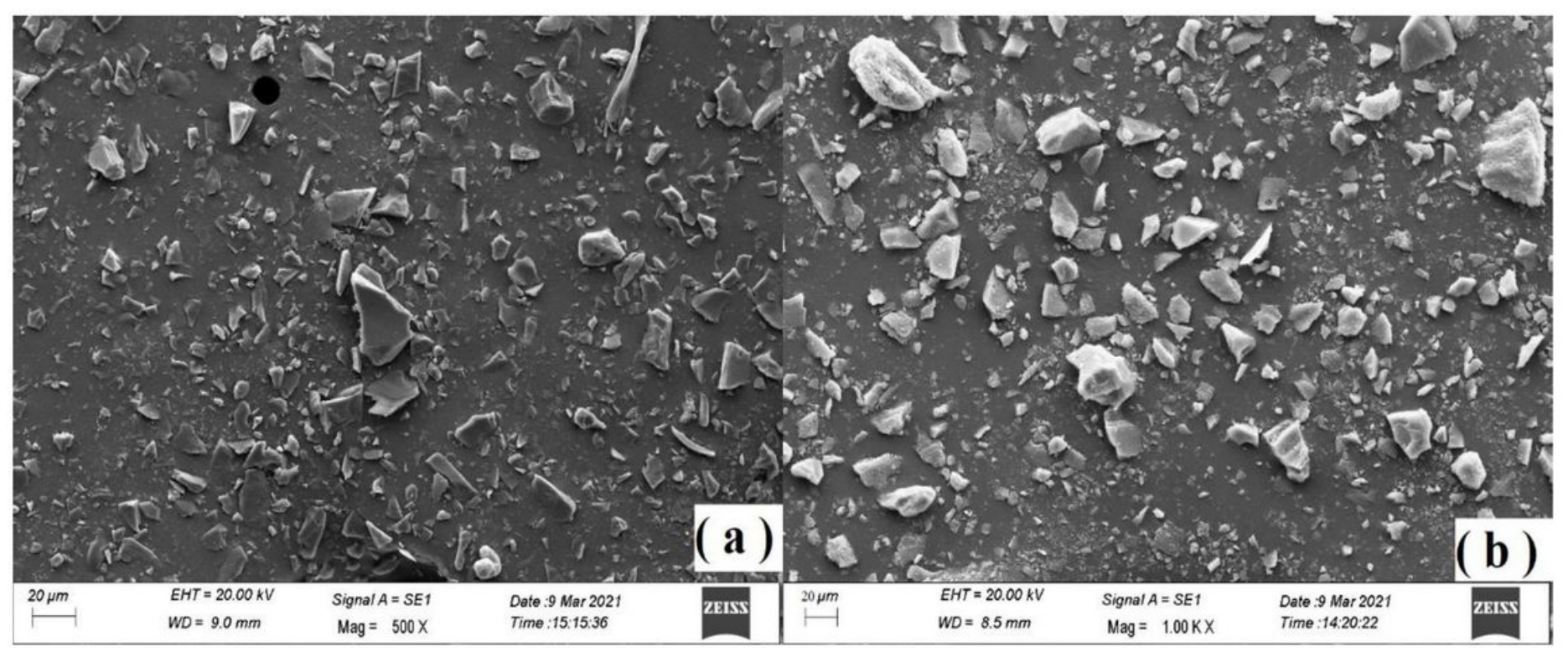

\section{Figure 1}

Particle sizes of (a) SiC reinforcement, (b) Kaoline reinforcement.

Aluminium Powder

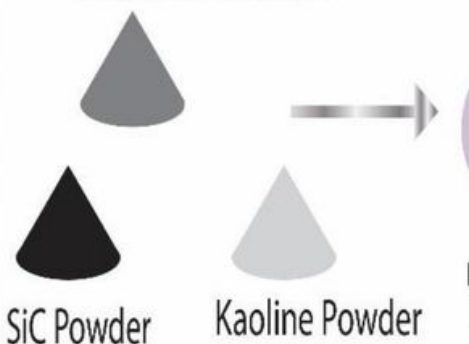

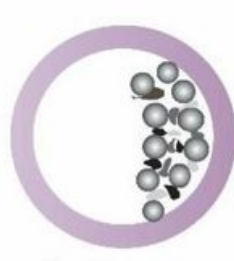

Ball Milling of Matrix and

Reinforcement Powders

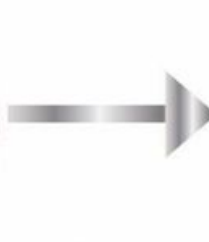

SEM analysis of composite Specimens
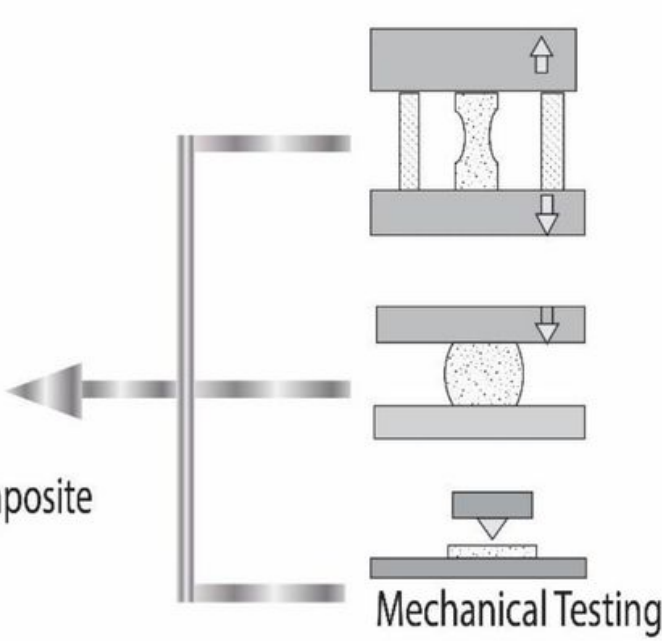

Composite Powder
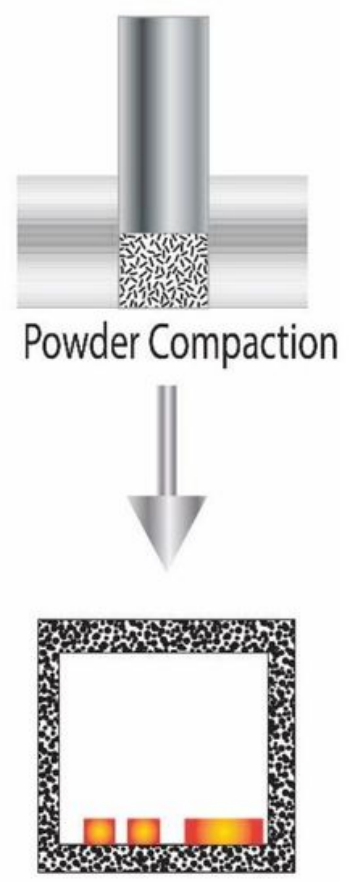

Sintering Of Composite Specimens

Figure 2 
Schematic diagram for powder metallurgy process
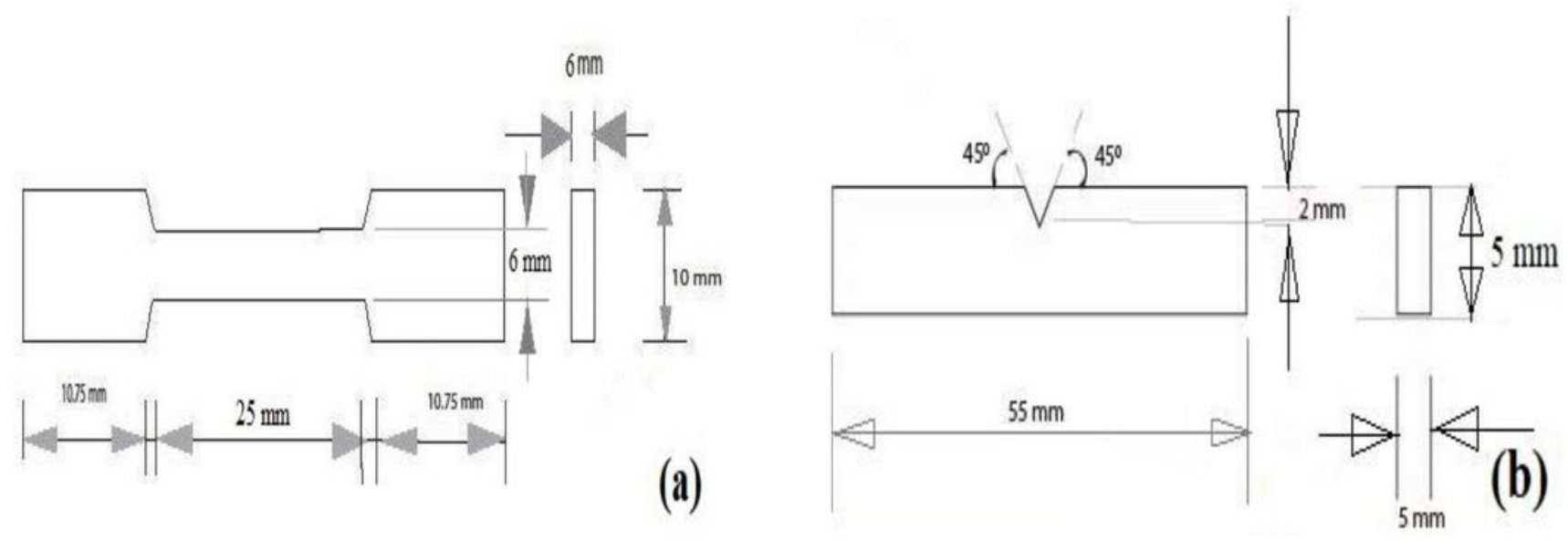

Figure 3

Specimen dimension dimensions for (a) Tensile test, (b) Impact Test

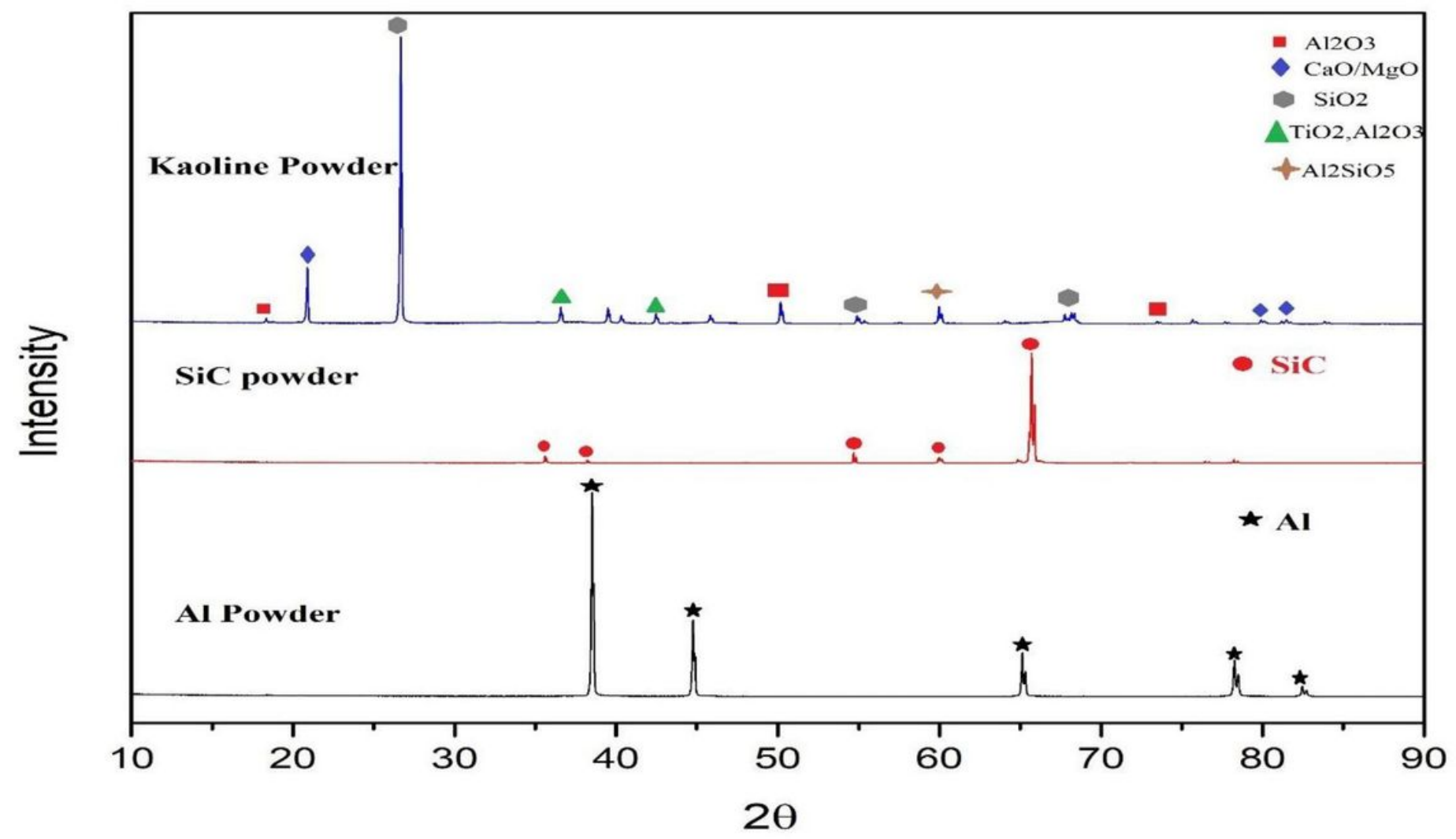

Figure 4

XRD pattern for as-received powders 


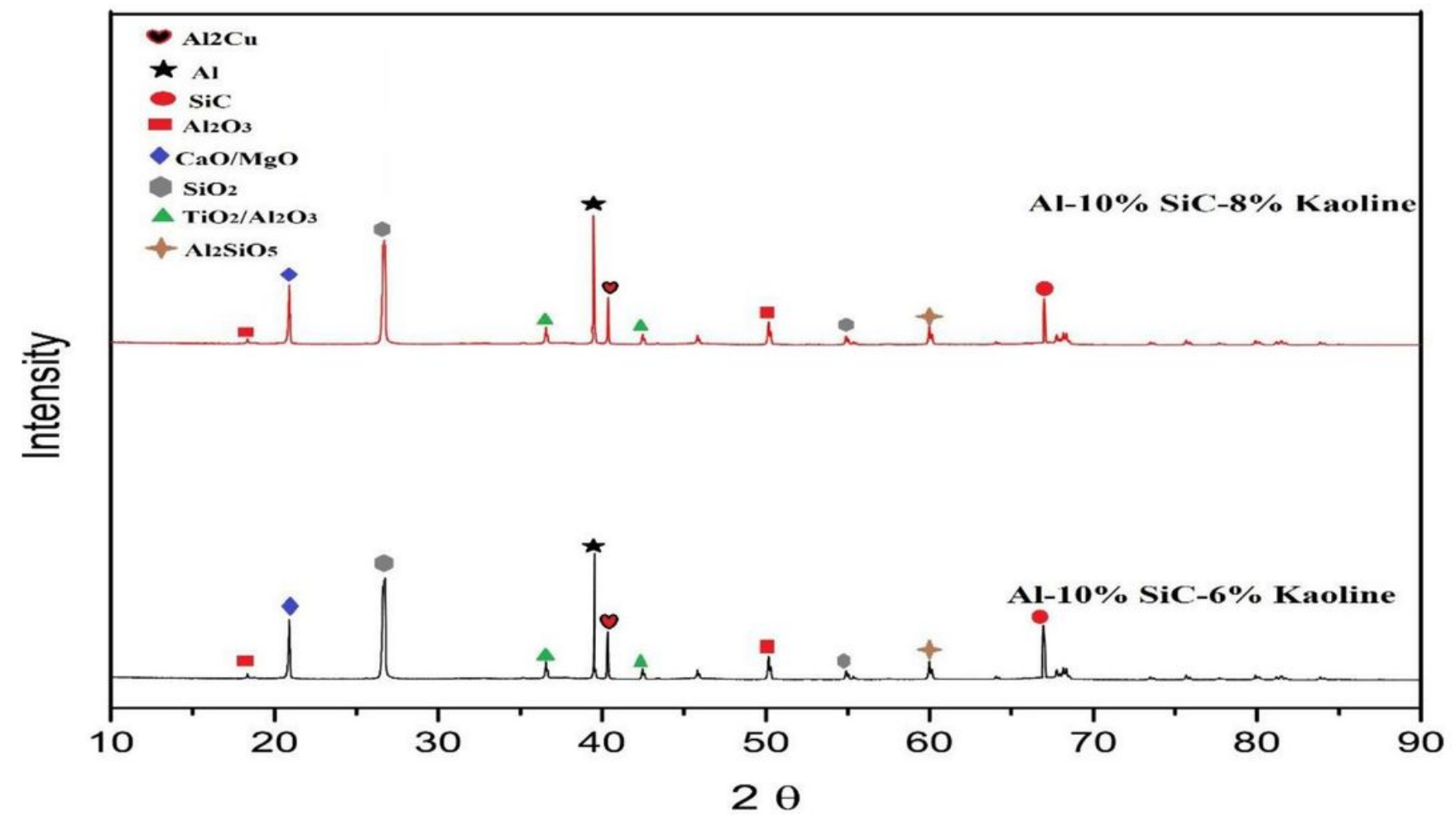

Figure 5

XRD patterns for fabricated samples 

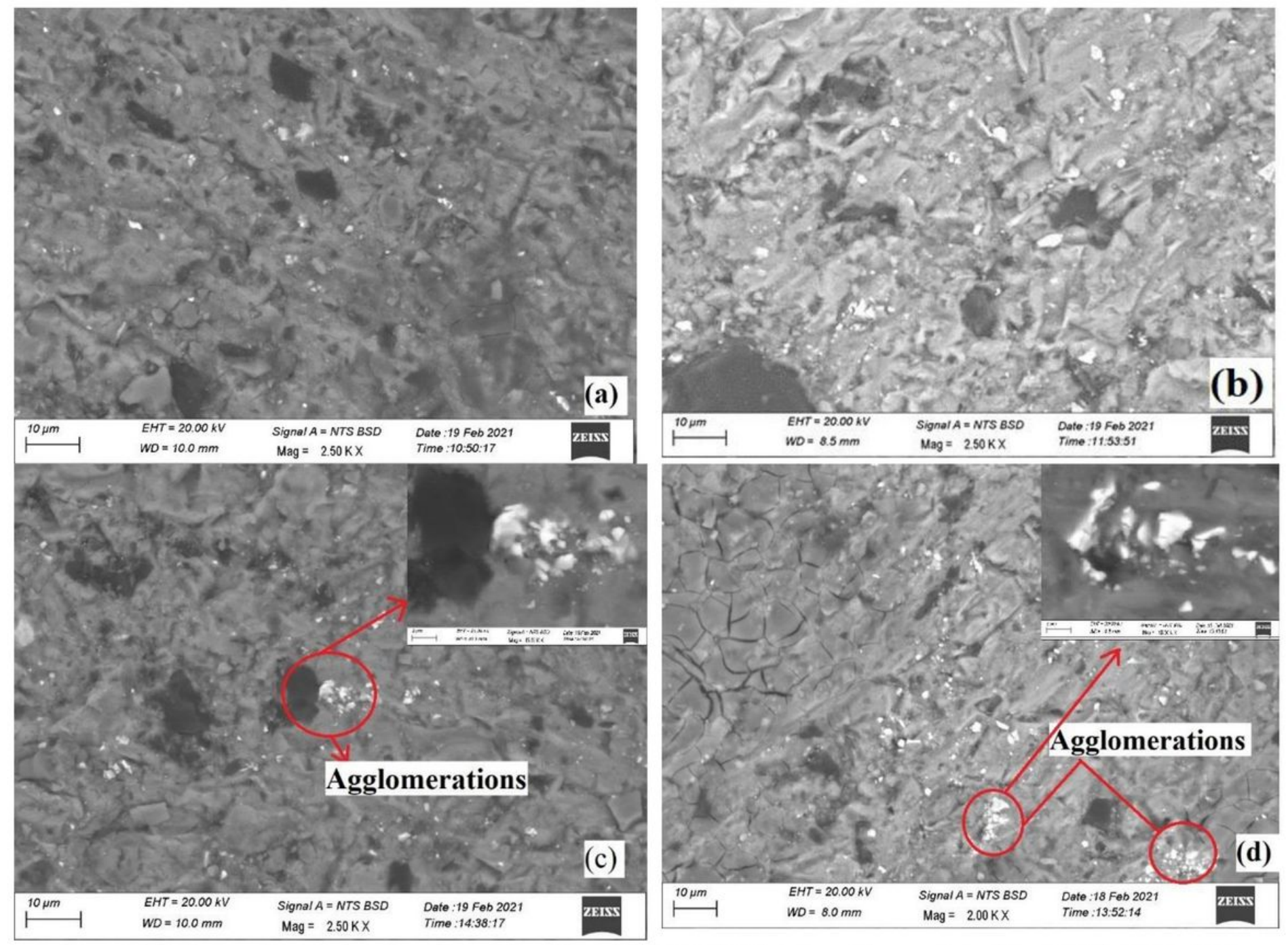

\section{Figure 6}

SEM micrographs for (a) Al-10\% SiC-2\% kaoline, (b) Al-10\% SiC-4\% kaoline, (c) Al-10\% SiC-6\% kaoline, (d) Al-10\% SiC-8\% kaoline 

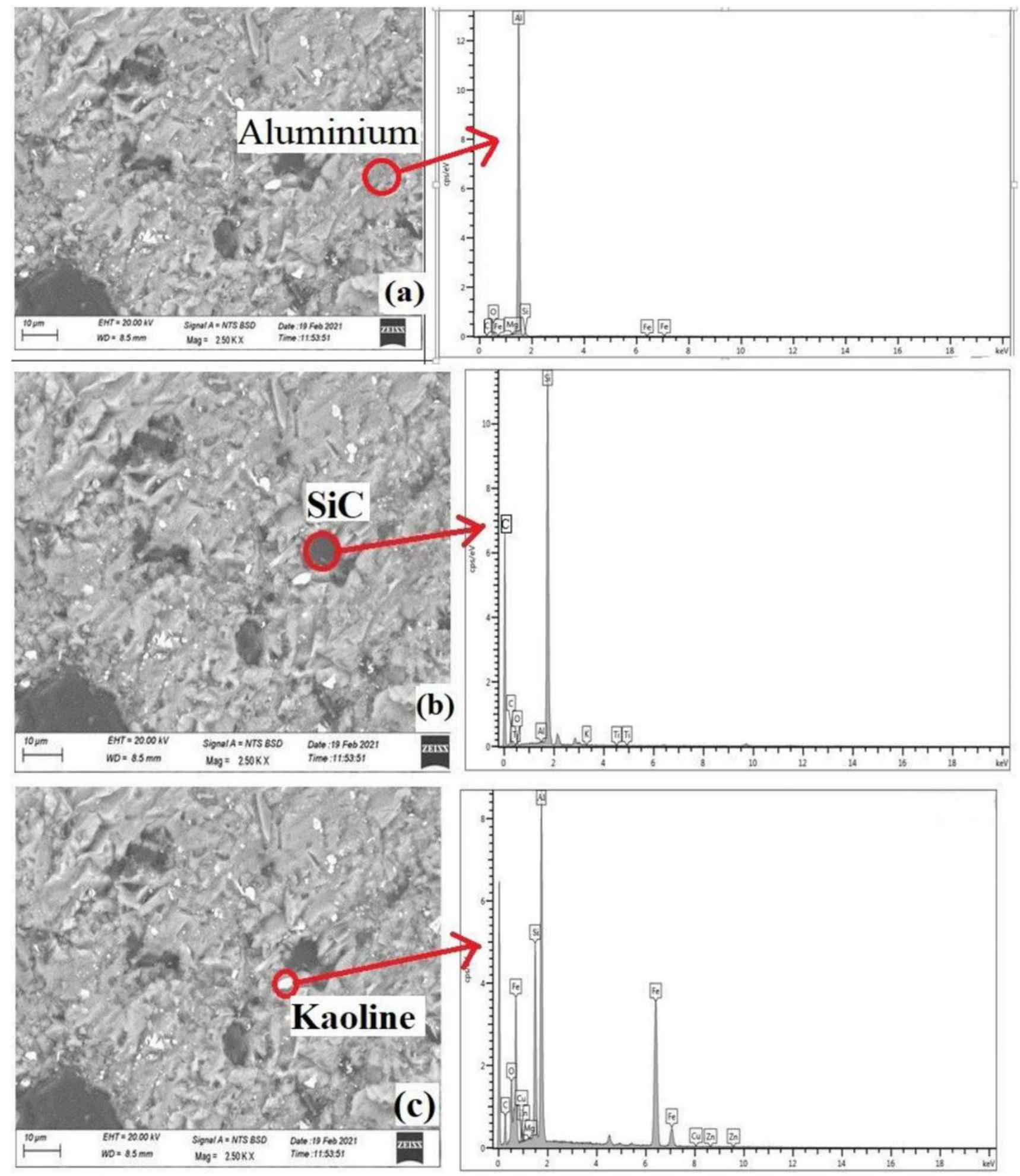

Figure 7

SEM and corresponding EDX pattern for (a) matrix Al, (b) SiC reinforcement, (c) Kaoline reinforcement in fabricated composite sample 


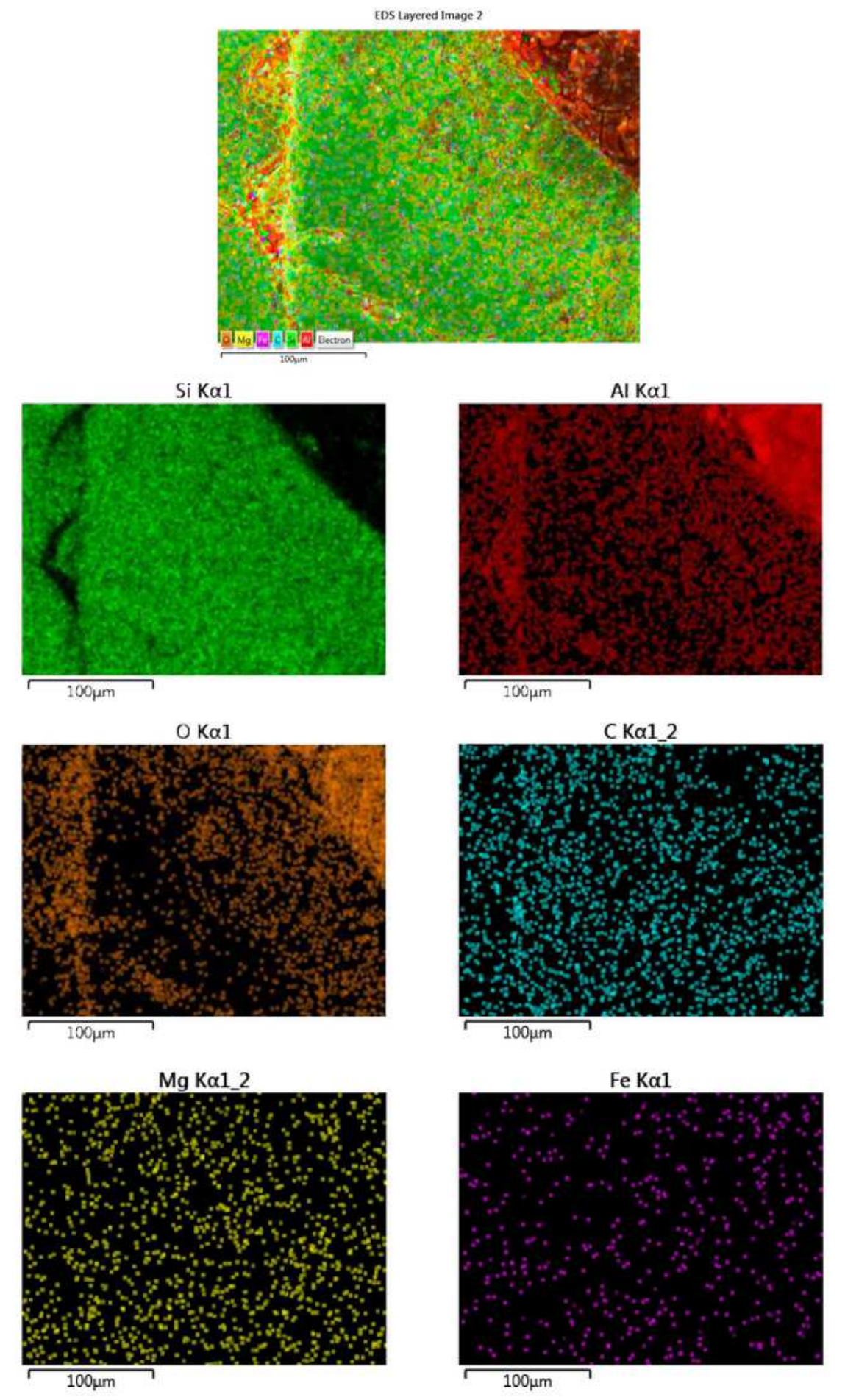

Figure 8

EDS mapping for the matrix and reinforcement interface 


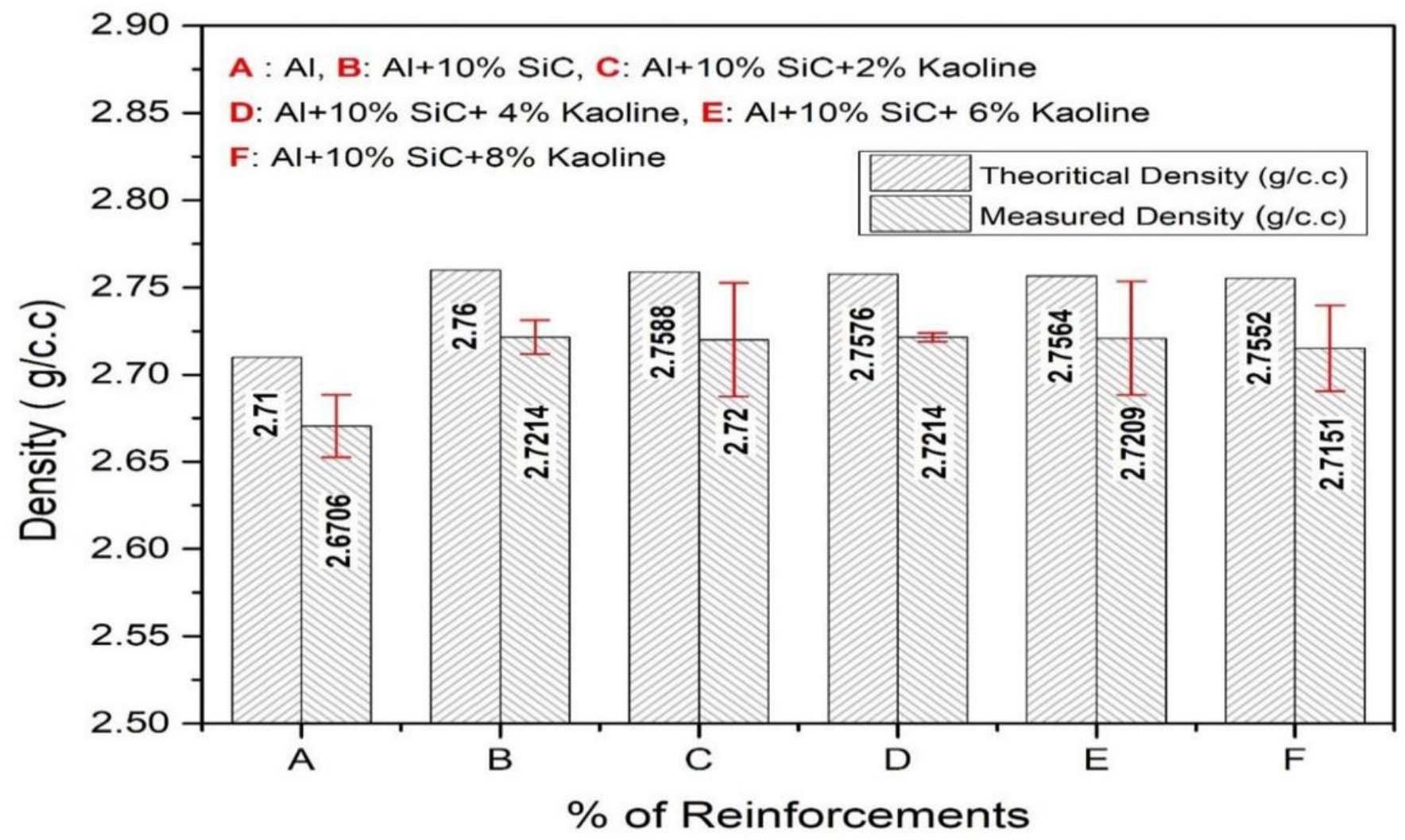

Figure 9

Variation of Density of HMMC with \% reinforcement 


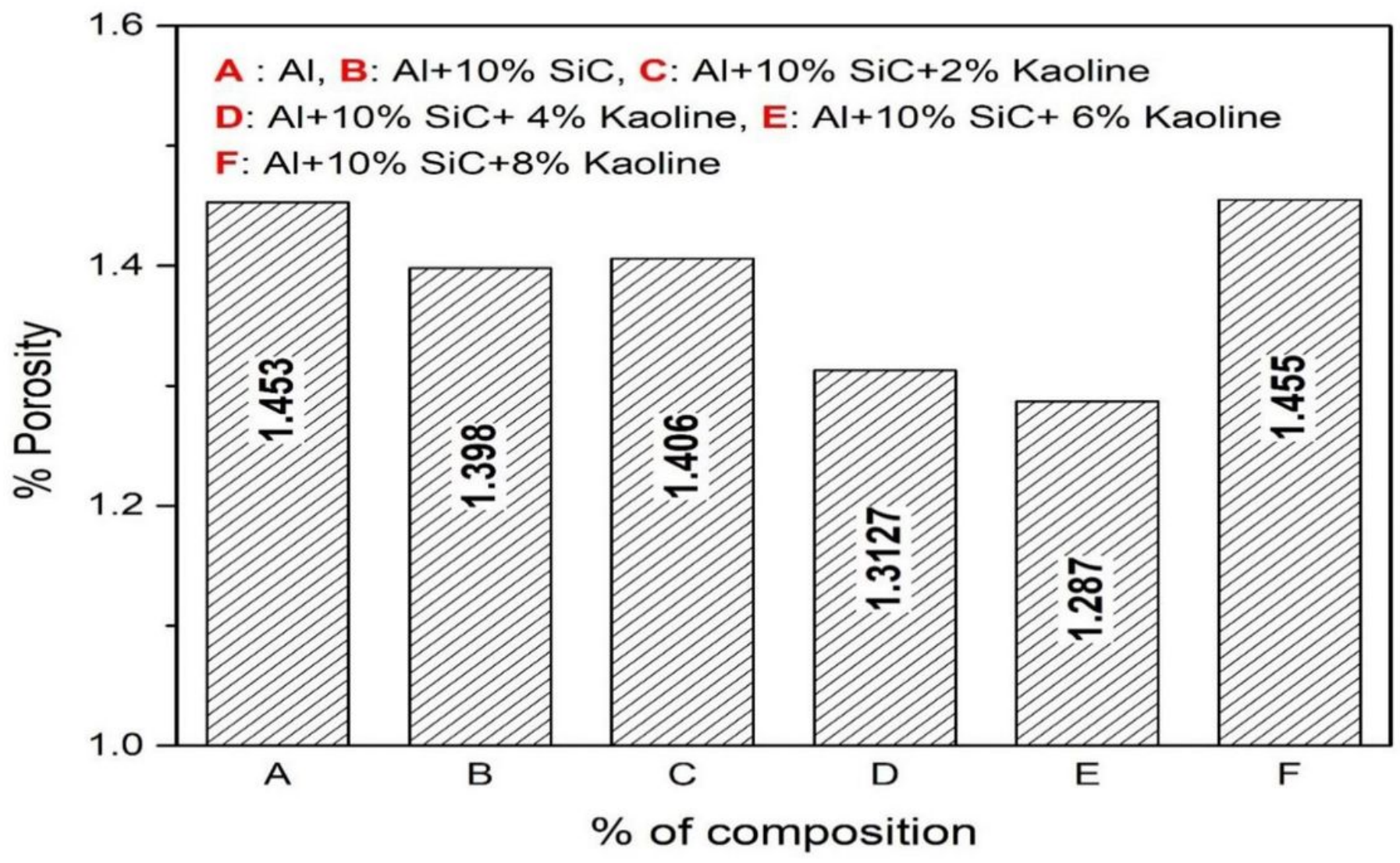

Figure 10

Variation of \% Porosity of HMMC with \% reinforcement 


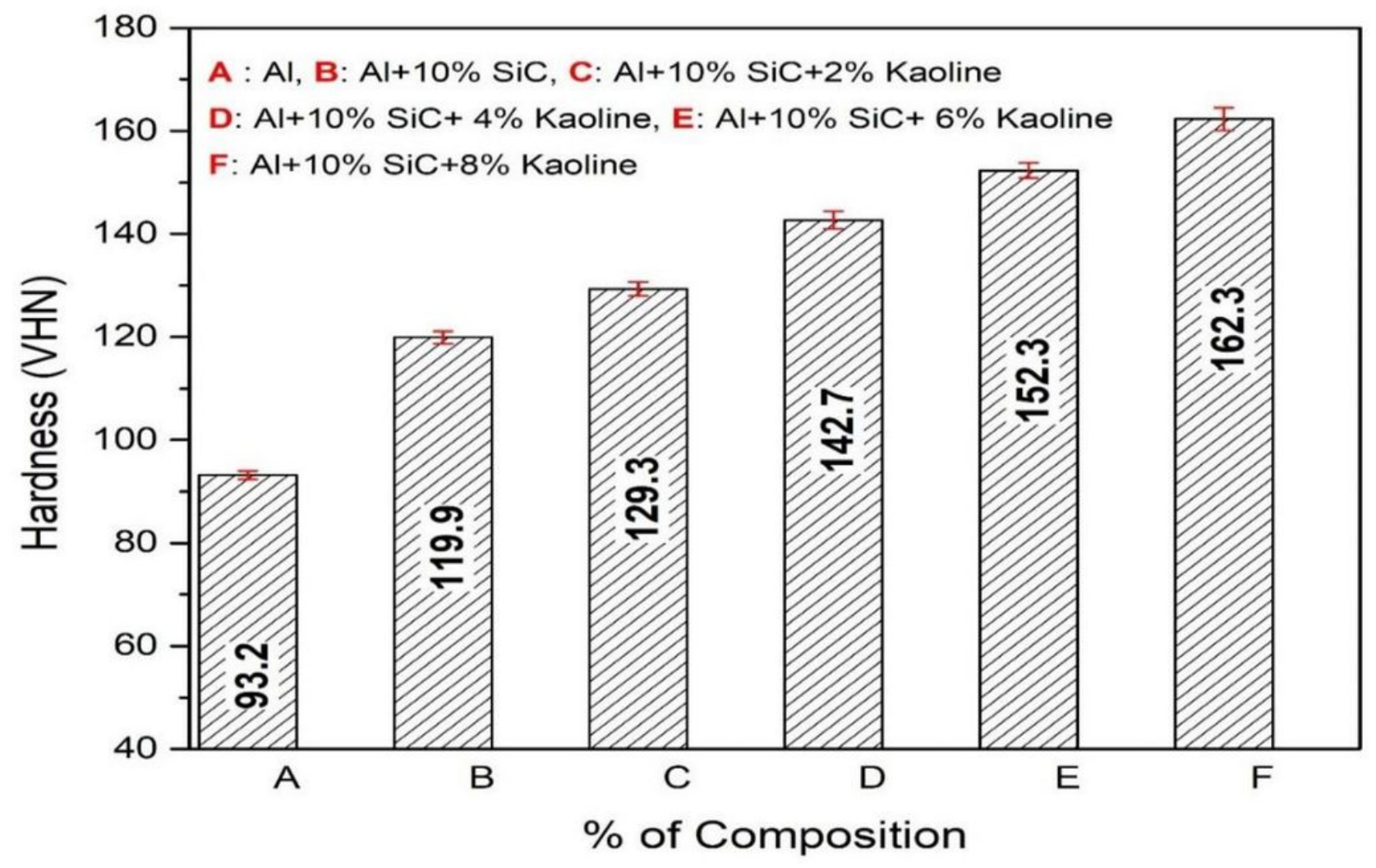

Figure 11

Variation of Hardness of HMMC with \% reinforcement 


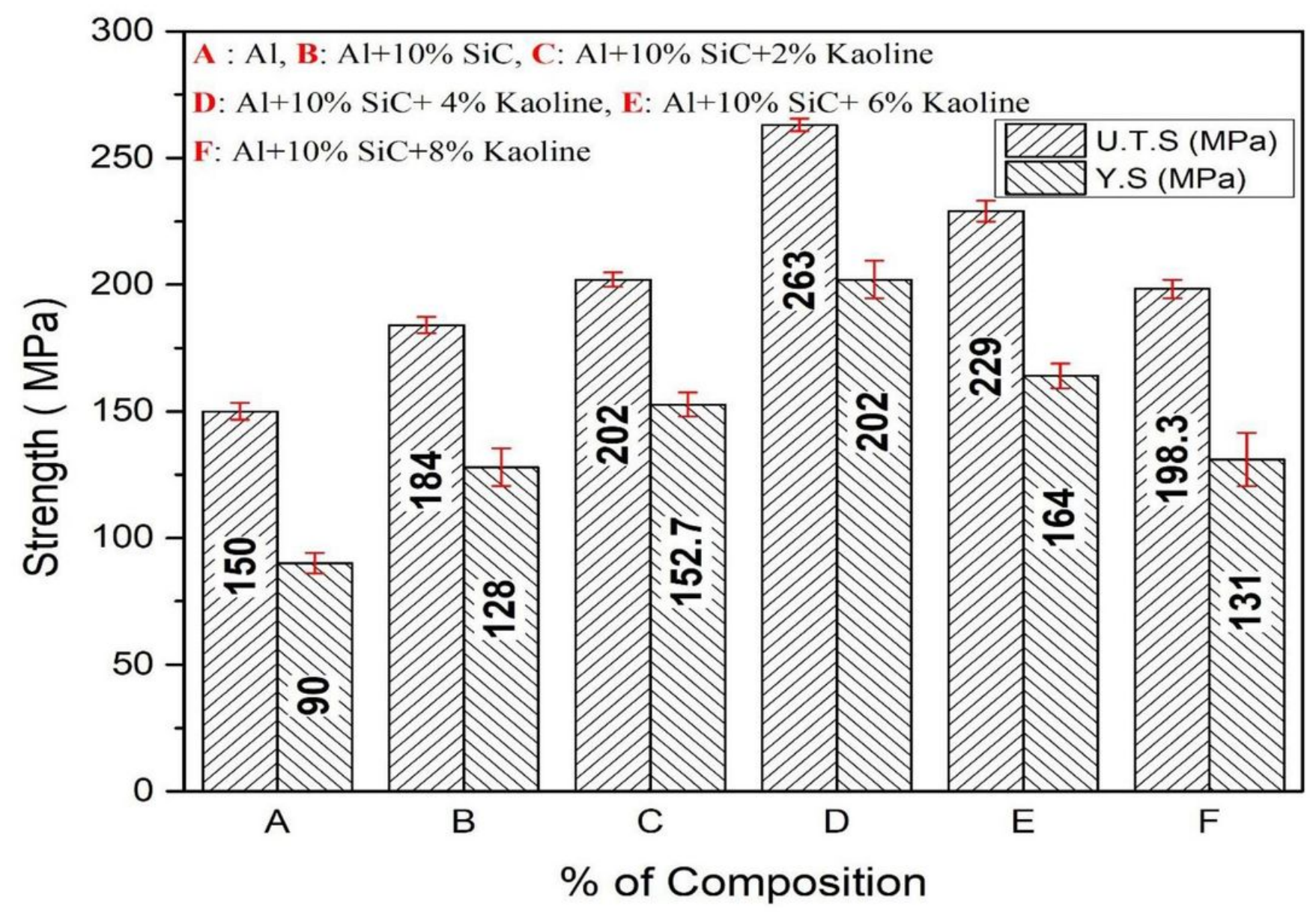

Figure 12

Variation of U.T.S and Y.S of HMMC with \% reinforcement 


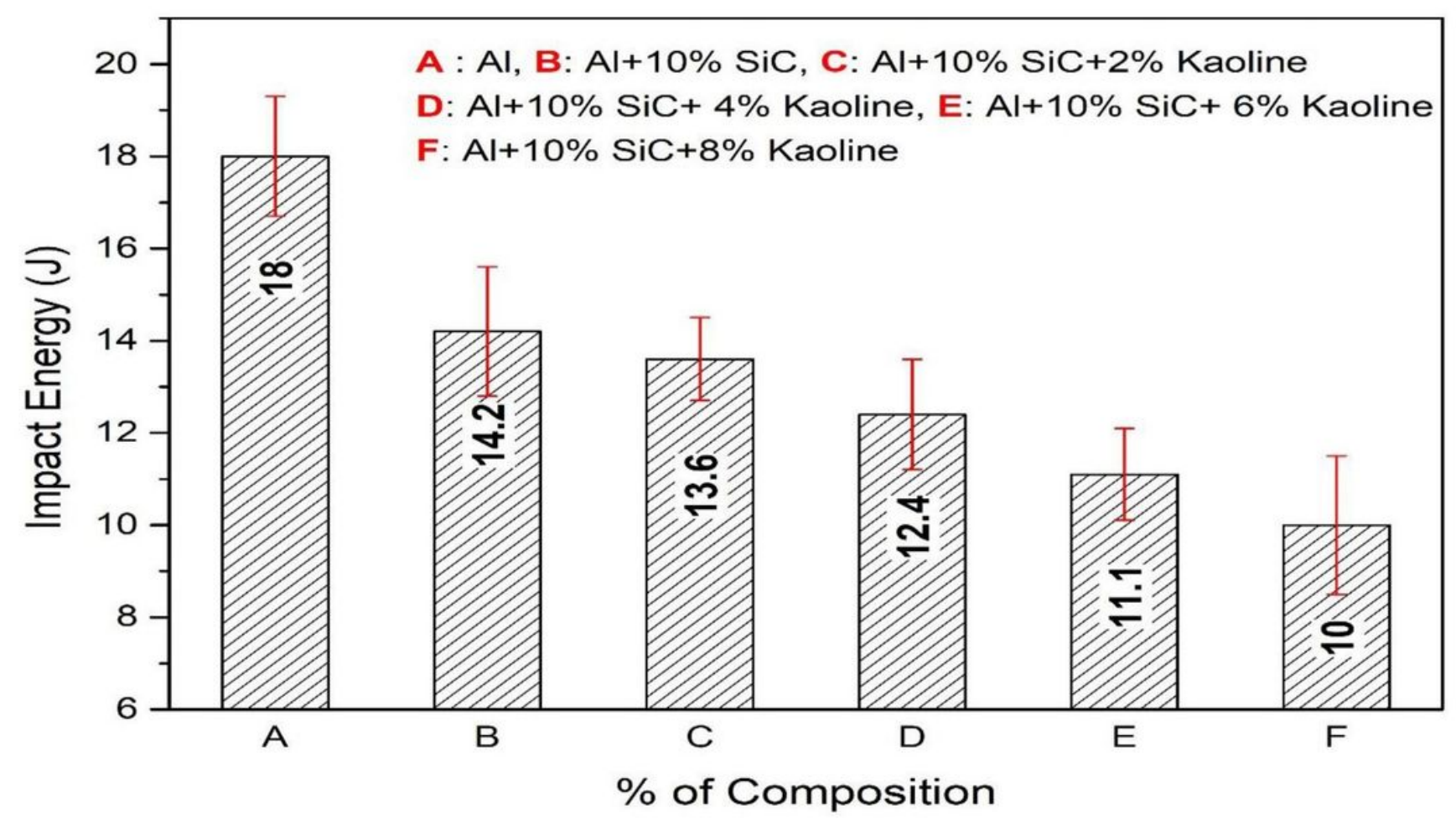

Figure 13

Variation of Impact energy of HMMC with \% reinforcement 

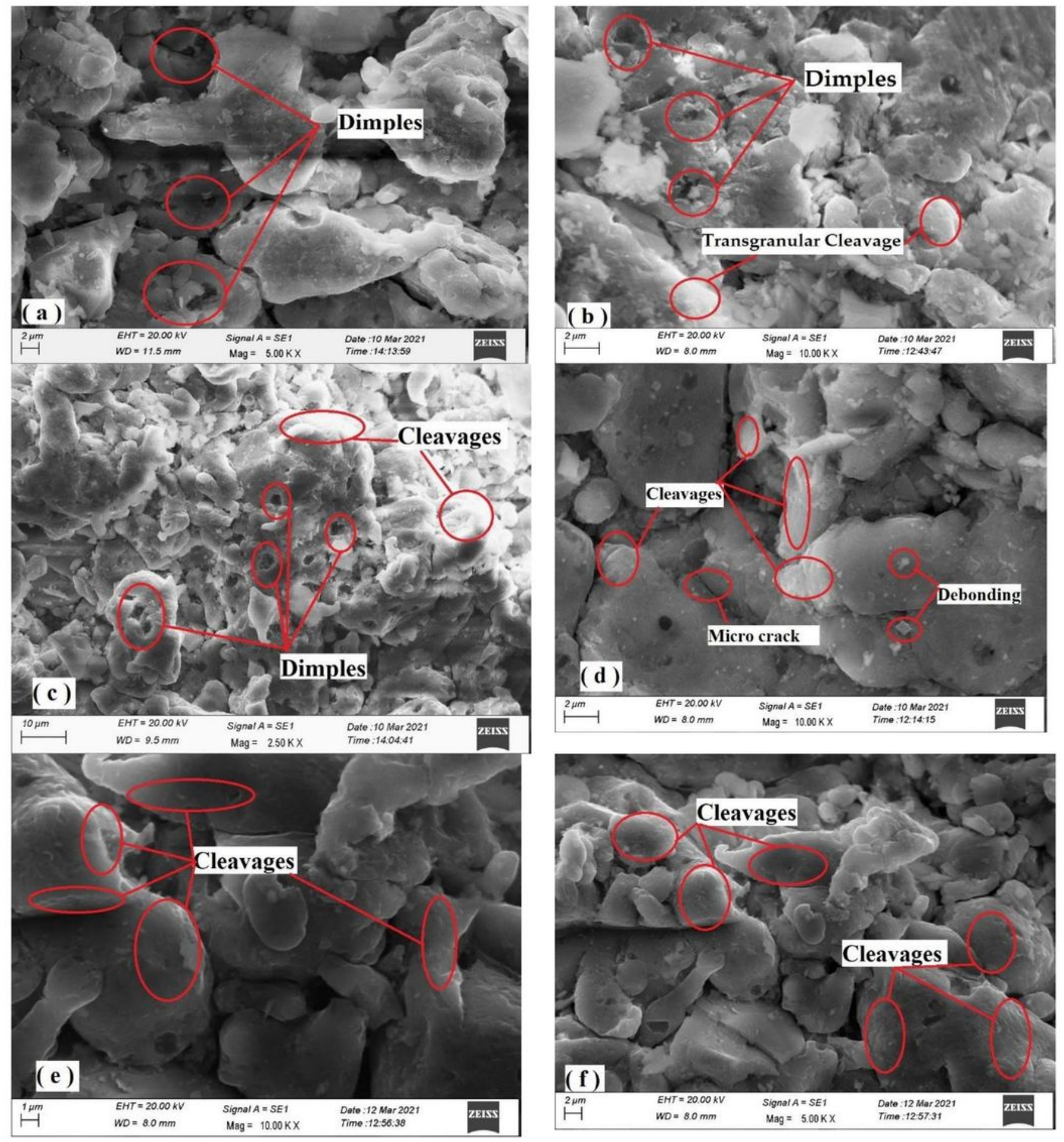

\section{Figure 14}

Fractured surface for (a) unreinforced Al, (b) Al-10\% SiC, (c) Al-10\% SiC-2\% Kaoline, (d) Al-10\% SiC-4\% Kaoline, (e) Al-10\% SiC-6\% Kaoline, (f) Al-10\% SiC-8\% Kaoline 